
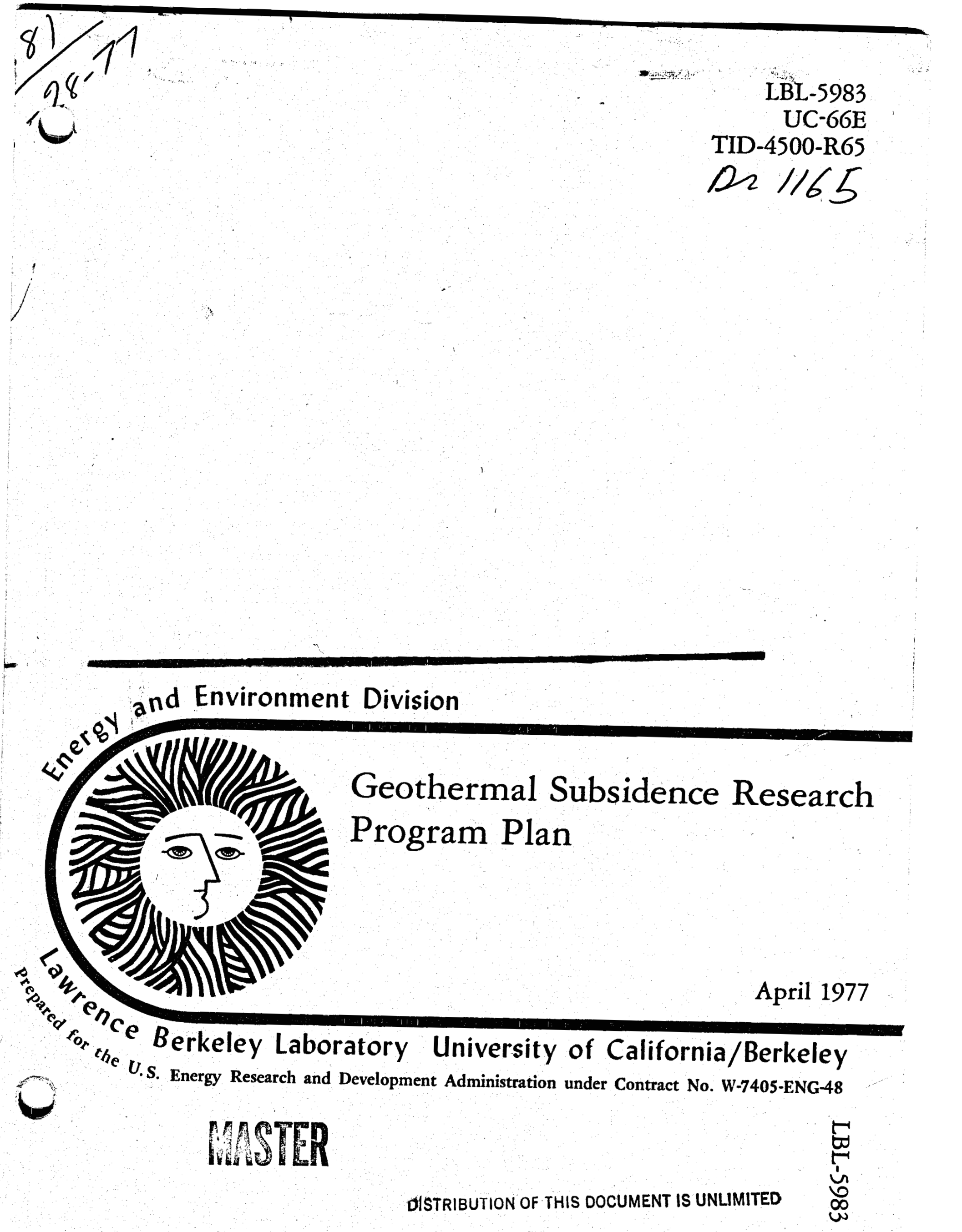


\section{DISCLAIMER}

This report was prepared as an account of work sponsored by an agency of the United States Government. Neither the United States Government nor any agency Thereof, nor any of their employees, makes any warranty, express or implied, or assumes any legal liability or responsibility for the accuracy, completeness, or usefulness of any information, apparatus, product, or process disclosed, or represents that its use would not infringe privately owned rights. Reference herein to any specific commercial product, process, or service by trade name, trademark, manufacturer, or otherwise does not necessarily constitute or imply its endorsement, recommendation, or favoring by the United States Government or any agency thereof. The views and opinions of authors expressed herein do not necessarily state or reflect those of the United States Government or any agency thereof. 


\section{DISCLAIMER}

Portions of this document may be illegible in electronic image products. Images are produced from the best available original document. 
LEGAL NOTICE

This report was prepared as an account of work sponsored by the United States Government. Neither the United States nor the United States Energy Research and Development Administration, nor any of their employees, nor any of their contractors, subcontractors, or their employees, makes any warranty, express or implied, or assumes any legal liability or responsibility for the accuracy, completeness or usefulness of any information, apparatus, product or process disclosed, or represents that its use would not infringe privately owned rights.

Printed in the United States of America

Available from

National Technical Information Service

U.S. Department of Commerce

5285 Port Royal Road

Springfield, Virginia 22161

Price: Printed Copy $\$ 5.50$; Microfiche $\$ 2.25$ 
LBL-5983

UC 66E

TID-4500-R65

\section{GEOTHERMAL SUBSIDENCE \\ RESEARCH PROGRAM PLAN \\ April 1977}

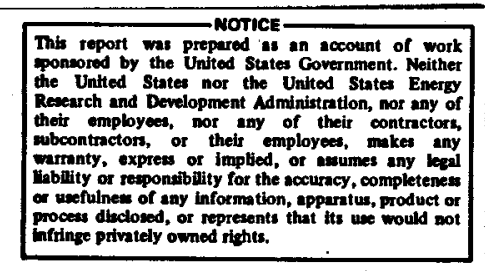

Energy and Environment Division Lawrence Berkeley Laboratory 1 Cyclotron Road Berkeley, California 94720

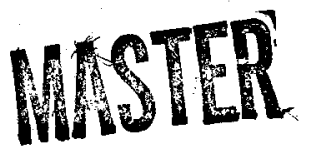

(415) 843-2740) 


\section{Preface}

This document takes a major research issue, potential subsidence from geothermal energy production, and develops a comprehensive research program to investigate subsidence. The viewpoints considered were those of the developer of an energy facility and those of the policy maker who regulates such facilities.

The research projects contained in this program plan were prepared so research may be contracted to selected capable organizations.

The work was sponsored by Mr. Ronald R. Loose and Dr. Allan Jelacic from the Energy Research and Development Administration, Division of Geothermal Energy.

Two teams of professionals were used to develop the program plan. One team prepared the plan; the other reviewed the plan and recommended changes. The program planning team consisted of Lawrence Berkeley Laboratory personnel with technical support from key non-laboratory individuals. Members of the planning team from the laboratory were:

Dr. Marcelo J. Lippmann

Dr. T. N. Narasimhan

Dr. Ronald schroeder

Mr. Terrance L. Simkin, Project Manager

Dr. Chin-Fu Tsang

Dr. Paul A. Witherspoon 
Non-laboratory support personnel who assisted the program planning team were:

Dr. Donald C. Helm, United States Geological Survey Dr. Robert Houston, University of California, Berkeley Dr. W. Scott Reys, United States Geological Survey Mr. Peter Klock, Energy Services Consulting

Dr. James Mitchell, University of California, Berkeley Mr. J. F. Poland, United States Geological Survey, Retired Mr. F. S. Riley, United States Geological Survey The review team was composed of individuals from industry, academic, and government organizations:

Mr. Dennis Allen, Dept. of Oil Properties, City of Long Beach Mr. Robert C. Erickson, Standard Oil Company of California (Team Chairman) Mr. Clarence Hottman, Shell Oil Company Dr. Paul H. Jones, Louisiana State University Mr. B. F. Lofgren, United States Geological Survey Dr. Denis Norton, University of Arizona Mr. H. (Don) Outmans, Union Oil Mr. Delbert Pyle, Union Oil Dr. R. F. Scott, California Institute of Technology The review team supplied assessments and recommendations during the development of the program plan. A jointly drafted acceptance 
letter was prepared. This letter has been reproduced as Figure A-4 in Appendix $A$.

The personnel at the Lawrence Berkeley Laboratory would like to express their appreciation for the assistance of those individuals who helped develop and review this plan. 


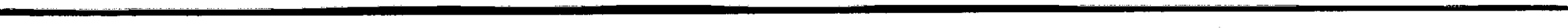




\section{Contents}

Preface ......................... iii

1. INTRODUCTION ................... 1

2. FRAMEWORK FOR PLANNING . . . . . . . . . . . . . 3

3. RESEARCH SCHEDULE AND MILESTONES . . . . . . . . . . . 13

APPENDIX A. RESEARCE PROGRAM PLAN DEVELOPMENT . . . . . . . 15

APPENDIX B. RESEARCH CATEGORIES . . . . . . . . . 25

1. Case Histories of Subsiding Areas and Geothermal

Subsidence Potential Maps . . . . . . . . . . . 25

Project 1-Subsidence Case Histories . . . . . . . . 25

Project 2-Geothermal Subsidence Potential Maps. . . . 29

2. Field Measurement Programs . . . . . . . . . . 37

Project-1 Criteria to Distinguish Between Subsidence

Caused by a Geothermal Project and Subsidence

Due to Other Causes . . . . . . . . 37

Project-2 Monitor Horizontal and Vertical Displacement. 50

3. Direct Monitoring Instrumentation . . . . . . . . 59

Project-1 Assess the State of the Art . . . . . . . 66

Additional Projects-Develop Prototypes and Conduct Field

Testing .......... 67

4. Environmental and Economic Effects . . . . . . . 71

Project 1-Collect Available Data . . . . . . . . 74

Project 2-Investigate Effects ........... 76

5. Physical Processes of Subsidence . . . . . . 79

6. Indirect Techniques to Estimate Subsidence at Depth . . 85

Project 1-Assess Indirect Techniques ........ 89

Project 2-Develop Prototypes and Testing. . . . . 89

7. Laboratory Testing . . . . . . . . . . 91

8. Subsidence Models . . . . . . . . . . . 95

9. Reservoir Operational Control Policy . . . . . . 107

Project 1-Industry Evaluation . . . . . . . . . . 108

Project 2-Guidelines and Procedures . . . . . . 110 


\section{INTRODUCTION}

\section{Rationale}

New energy sources must be developed. Under the direction of the Energy Research and Development Administration (ERDA), the development of energy sources is moving ahead in a number of fields, such as solar, geothermal, coal, and nuclear energy. Many opportunies are avaliable for development of the resources; however, there are problems. One such problem is land deformation that may accompany removal or injection of fluids from or into geothermal reservoirs. The issue of land deformation, commonly referred to as subsidence, is the focus of this research program plan.

Unexpected and uncontrolled subsidence may have social, environmental, and economic consequences. However, subsidence occurring under controlled conditions may be acceptable. The impacts can vary greatly, based on geological and land-use settings. Damages associated with the subsidence at the wilmington oil Field in California represent one extreme. The center of the subsidence depression has dropped over 9 meters (29 ft) since 1926 within the city of Long Beach. Horizontal movements of nearly 3 meters (10 ft) have also been measured. These movements have damaged wharves, pipelines, buildings, streets, bridges, and wells, necessitating costly repairs, including the raising of the land surface to prevent inundation by the sea. Damages have exceeded $\$ 100$ million. 1 
On the other extreme, movement as much as several meters due to groundwater withdrawal in agricultural areas of California and Arizona has left little or no reported impact. ${ }^{2}$

Potential geothermal resource areas may be found in many different geological and land-use settings. Thus, subsidence may or may not be an issue of major concern. The degree of concern attached to subsidence will depend on an assessment of subsidence potential at each geothermal site. The research program contained in this plan seeks to enable such assessments to be made with confidence.

\section{Program Objective}

The objective of geothermal subsidence research is to control or mitigate potential subsidence associated with geothermal development within predictable limits. In this way, geothermal programs may proceed without delays and siting flexibility may be increased.

Successful subsidence research will provide:

- The means for developers to build and operate geothermal facilities within prescribed limits of potential subsidence.

- The basis for policy makers to regulate geothermal facilities with respect to potential subsidence.

\section{REFERENCES}

1. "Subsidence in the Wilmington Oil Field, Long Beach, California, USA," by M. N. Mayuga and D. R. Allen, in Land subsidence, Proceedings of the Tokyo Symposium, Sept. 1969, Vol. 1, pp. 66-67, published by the International Association of Scientific Hydrology.

2. C. McCauley and R. Gum, "Land Subsidence. An Economic Analysis," Water Res. Bull, Am. Water Res. Assoc. 11, No. 1 (1975). 


\section{FRAMEWORK FOR PLANNING}

Research Program Structure

The ultimate goals of the subsidence research program are to understand and control subsidence associated with geothermal energy development. These goals may be stated more precisely:

- Distinguish naturally occurring subsidence from that possibly caused by geothermal operations.

- Operate a geothermal well fleld in a manner that will prevent or minimize adverse effects due to subsidence.

Both goals are assessed to be achievable within the structure of the research program created by this plan.

The Subsidence Research Program is an integrated structure consisting of five major elements:

- Characterization of Subsidence

- Physical Theory of Subsidence

- Properties of Materials

- simulation of Subsidence

- Subsidence Control

These elements contain research categories, which define the thrust and direction of the research program. Research categories in turn are composed of individual research projects. The three levels of the program are illustrated in Figure 2-1. The number of components in each level varies with the research subject matter. For subsidence there are five program elements, nine categories, and sixteen projects. 
The elements and their research categories are described on the following pages.

\section{A. CHARACTERIZATION OF SUBSIDENCE}

This structural element is concerned with the measurement of subsidence and subsidence effects. The intent of its research categories is to characterize the subsidence phenomenon or provide the means to attain that characterization. The element consists of four research categories:

\section{Case Histories of Subsiding Areas and Geothermal Subsidence Potential Maps}

As the name implies, the category involves research to document cases of known subsidence and mapping areas of geothermal subsidence potential. The research will provide knowledge of subsidence potential in different geological environments.

\section{Field Measurement Programs}

Subsidence baseline monitoring surveys le.g., horizontal triangulation, vertical leveling) are needed to:

- Measure the degree of subsidence due to geothermal activities as opposed to other man-induced or natural subsidence.

- Establish the background rate of land deformation. This category is concerned with providing baseline monitoring information in known and prospective geothermal areas. Much of the work associated with baseline monitoring is the responsibility of federal agencies, such as the National Geodetic Survey and the U. S. Geological survey. These agencies are engaged in monitoring surveys at 
or near geothermal areas. This research category will assure that the surveys provide comprehensive and timely monitoring information.

\section{Direct Monitoring Instrumentation}

Direct observations at depth are necessary to relate subsurface compaction to surface subsidence. Such observations require instrumentation to accurately measure vertical distances between points in wells and drill holes. The development of such instrumentation is the subject of this research category.

\section{Envirommental and Economic Effects}

Subsidence is a problem in geothermal development only to the extent that it produces undesirable environmental and economic consequences. Hence an understanding of possible effects from subsidence in different settings is essential. This research category is concerned with collecting economic data and investigating the effects of potential geothermal-related subsidence.

\section{B. PHYSICAL THEORY OF SUBSIDENCE}

Sound physical theory is a vital element of any technical research effort. Research to understand the physical processes that cause subsidence belongs in this research element.

\section{Physical Processes of Subsidence}

This category involves assessing current theory about the physical processes of subsidence and to correct deficiencies in that 
theory. The theoretical studies will include both the response of geologic materials to stress fields and the nature of induced movements along fracture systems.

\section{PROPERTIES OF MATERIALS}

Subsidence is a response of geologic materials to some external perturbation such as the removal of geothermal fluids. Element B dealt with the physical theory of responses by perturbed materials. This element deals with the material properties that affect those responses. This element contains two research categories:

\section{Indirect Measurements}

Certain physical properties of geothermal reservoirs, such as porosity, flow rate, and pressure, may provide indirect evidence of compaction. If these properties are monitored over time, they could be used as subsidence indicators within the reservoir. However, in most cases the instruments or techniques needed to monitor reservoir properties are inadequate or nonexistent. This research category involves developing and testing instrumentation that will accurately measure certain reservoir properties. The identity and monitoring specifications of these properties will depend on a subsidence model. This model will use physical theory that relates the properties to reservoir deformation.

\section{Laboratory Testing}

At present some properties of geothermal reservoirs are not directly measurable in the field. These properties include 
characteristics of the rock materials such as compressibility, permeability, and chemical reactivity. In order to measure such characteristics, a laboratory testing program using actual samples of materials is required. Thus the purpose of this research category is to produce a testing program that will give realistic measurements of material properties under simulated reservoir conditions. The measurements will provide valuable input to rock mechanics subsidence models.

\section{SIMULATION OF SUBSIDENCE}

simulation includes the mathematical modeling of subsidence and related phenomena. It is simply the useful application of physical theory. One or more reliable subsidence models comprise an essential element of the overall research program.

\section{Subsidence Models}

A number of subsidence models for geothermal reservoirs exist, but the applicability of these models remains in doubt. This research category supports studies to critically evaluate subsidence models and test them against hypothetical and actual field cases. If necessary, improvements to existing models or new model development may be included, pending the results of model evaluation.

\section{E. SUBSIDENCE CONTROL}

The last element is the target element of the research program. Within this element the program goals are attained. The other elements 
simply provide the supporting information needed to make those goals attainable. As stated previously, the goals are:

- Distinguish naturally occurring subsidence from that possibly caused by geothermal operation.

- Operate a geothermal well field in a manner that will prevent or minimize adverse effects due to subsidence.

\section{Reservoir Operational Control Policy}

This category includes background studies of reservoir management practices leading to the development of operation policies that minimize the effects of subsidence. Such policies are formulated with knowledge gained from the total research effort (e.g., models, baseline measurements, laboratory tests) and represent the culmination of that effort. Inherent in these policies are the abilities to separate natural from man-induced subsidence and then mitigate the man-induced portion.

The subsidence research program structure, including individual research projects, is illustrated in Table 2-I. Detailed specifications for the categories and projects are given in Appendix B.

\section{Research Program Integration}

The five elements of the Subsidence Research Program can be called "structural" elements because they comprise the structure or framework on which the program is built. They are analogous to the supports of a large building. In order for the structure to be sound, each 
element must tie to or support other elements. That is, the program must be properly integrated to assure that its goal will be achieved. The relationships in the Subsidence Research Program are best shown at the category level. Figure 2-2 illustrates how the 9 research categories integrate to form a comprehensive program. The diagram gives the approximate sequence of events leading to the program's goals.

Case histories of subsiding areas and geothermal subsidence potential maps (Research Category 1) along with field measurement programs (Research Category 2) are needed to characterize the amount of subsidence from geothermal operations. The results of those efforts provide essential information to formulate a theory of physical processes (Research Category 5) that cause subsidence. Physical processes of subsidence in turn dictate what indirect techniques to estimate deformation at depth (Research Category 6) and laboratory testing (Research Category 7) should be done, and all three yield information governing the development of subsidence models (Research Category B).

Case histories of subsiding areas and geothermal subsidence potential maps (Research Category 1) also help to define the environmental and economic effects of subsidence (Research Category 4). Field measurement programs (Research Category 2) determine the requirements for direct monitoring instrumentation (Research Category 3) that will detect subsidence activity at depth before that activity is manifest at the surface. 


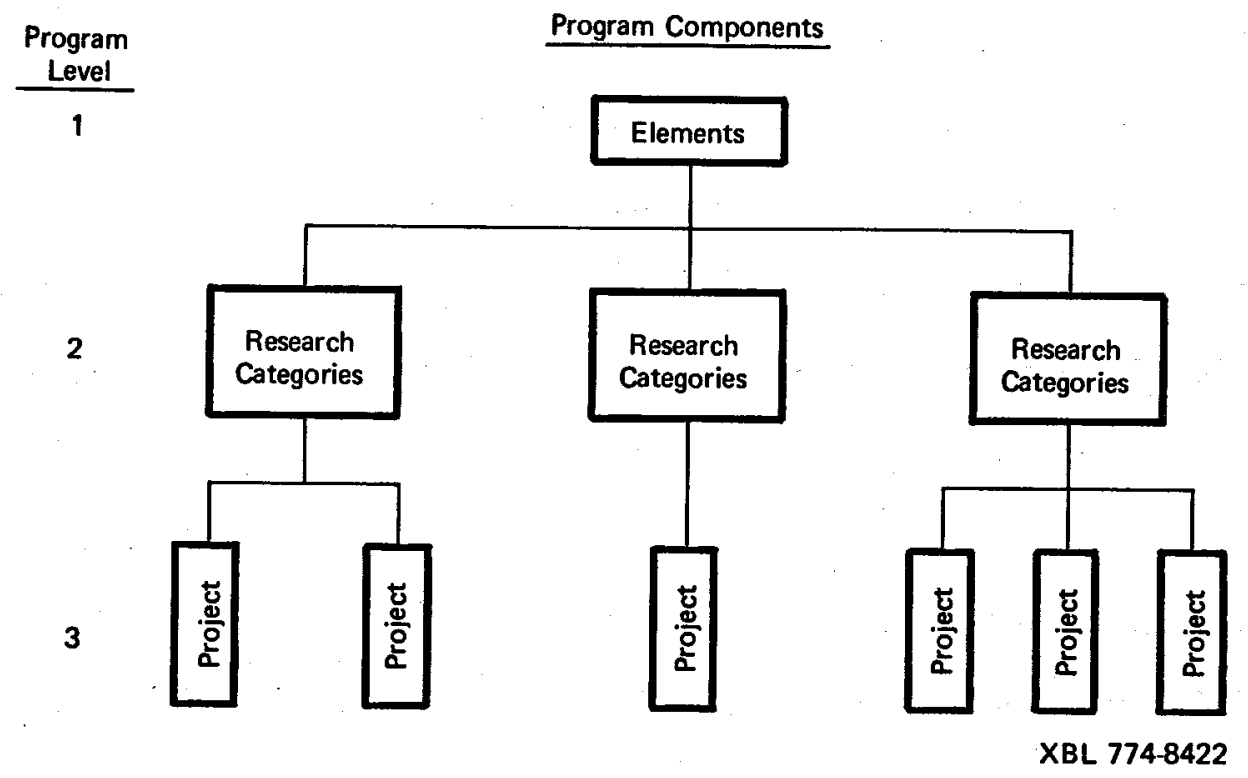

Figure 2-1. General Research Program Structure.

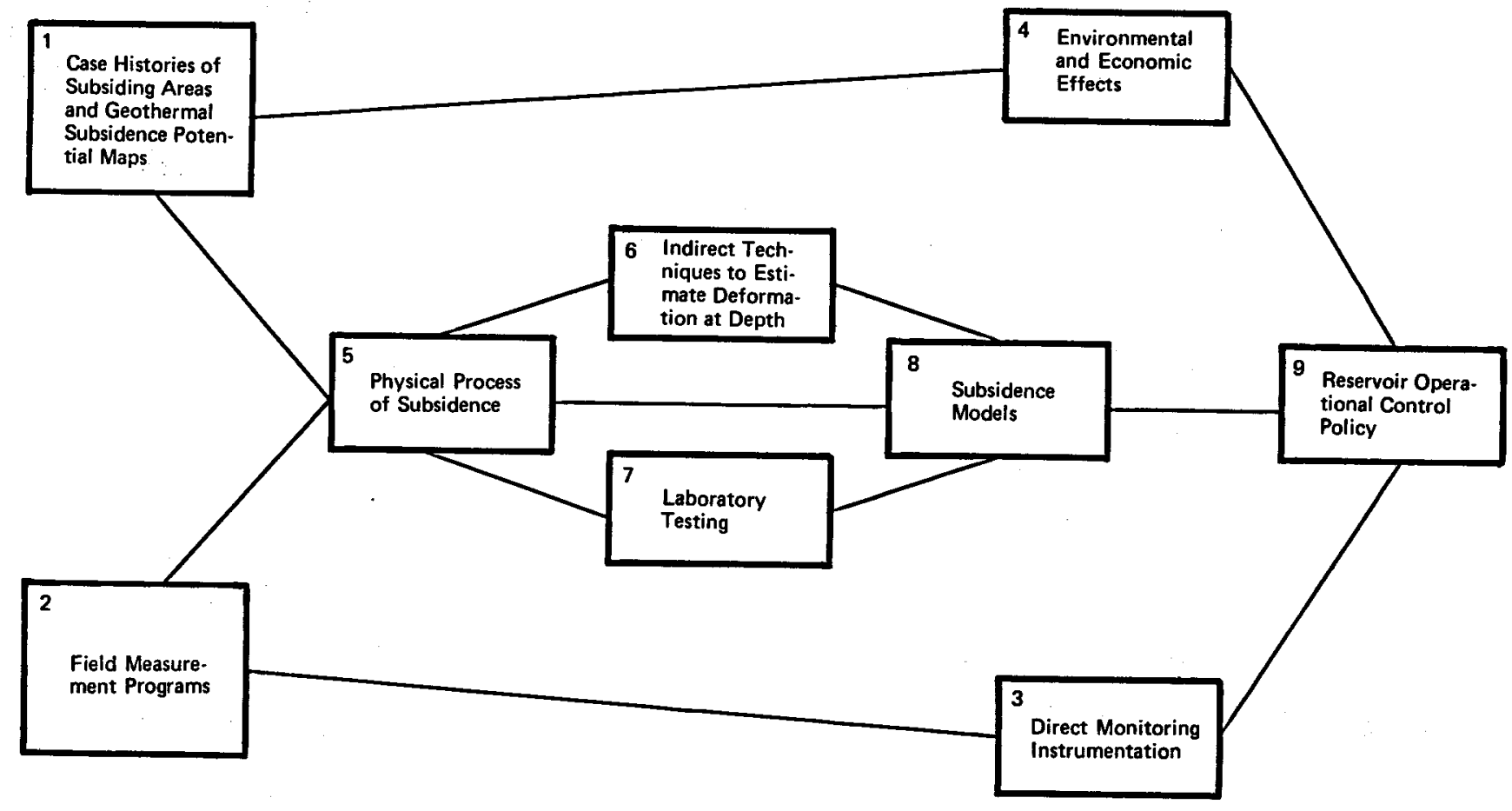

XBL 774-8423

Figure 2-2. Subsidence Research Program Integration at the Level of Research Categories. 
Table 2-I. The Three Levels of the Subsidence Research Program.

\begin{tabular}{|c|c|c|}
\hline Elements & Research Category & Projects \\
\hline $\begin{array}{l}\text { A. Characterization } \\
\text { of subsidence }\end{array}$ & $\begin{array}{l}\text { 1. Case Histories of } \\
\text { Subsiding Areas and } \\
\text { Geothermal Subsidence } \\
\text { Potential Maps }\end{array}$ & $\begin{array}{l}\text { 1. Land Deformation } \\
\text { Case Histories } \\
\text { 2. Geothermal Subsi- } \\
\text { dence Potential Maps }\end{array}$ \\
\hline 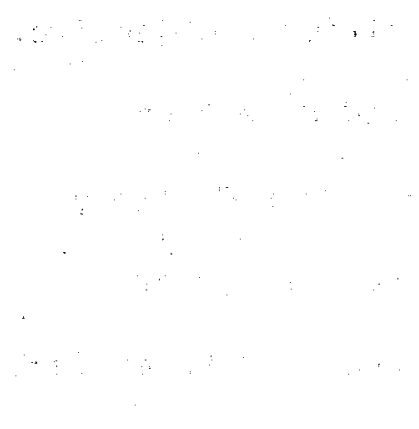 & $\begin{array}{l}\text { 2. Field Measurement } \\
\text { Programs }\end{array}$ & $\begin{array}{l}\text { 1. Criteria to } \\
\text { Distinguish Between } \\
\text { Potential Subsidence } \\
\text { Caused by a Geo- } \\
\text { thermal Project } \\
\text { and Subsidence Due } \\
\text { to Other Causes } \\
\text { 2. Monitor Horizontal } \\
\text { and Vertical } \\
\text { Displacement }\end{array}$ \\
\hline$\cdots$ & $\begin{array}{l}\text { 3. Direct Monitoring } \\
\text { Instrumentation }\end{array}$ & $\begin{array}{l}\text { 1. Assess the State } \\
\text { of the Art } \\
\text { 2. Develop Proto- } \\
\text { types and Conduct } \\
\text { Field Tests }\end{array}$ \\
\hline & $\begin{array}{l}\text { 4. Environmental and } \\
\text { Economic Effects }\end{array}$ & $\begin{array}{l}\text { 1. Data Collection } \\
\text { 2. Investigate } \\
\text { Effects }\end{array}$ \\
\hline $\begin{array}{l}\text { B. Physical Theory } \\
\text { of Subsidence } \\
\end{array}$ & $\begin{array}{l}\text { 5. Physical Processes of } \\
\text { Subsidence }\end{array}$ & $\begin{array}{l}\text { Same as Research } \\
\text { Category }\end{array}$ \\
\hline $\begin{array}{l}\text { C. Properties of } \\
\text { Materials }\end{array}$ & $\begin{array}{l}\text { 6. Indirect Techniques to } \\
\text { Estimate Subsidence at } \\
\text { Depth }\end{array}$ & $\begin{array}{l}\text { 1. Assess Indirect } \\
\text { Techniques } \\
\text { 2. Develop Proto- } \\
\text { types }\end{array}$ \\
\hline & 7. Laboratory Testing & $\begin{array}{l}\text { Same as Research } \\
\text { Category }\end{array}$ \\
\hline $\begin{array}{l}\text { D. Simulation of } \\
\text { Subsidence }\end{array}$ & 8. Subsidence Models & $\begin{array}{l}\text { Same as Research } \\
\text { Category }\end{array}$ \\
\hline $\begin{array}{l}\text { E. Subsidence } \\
\text { Control }\end{array}$ & $\begin{array}{l}\text { 9. Reservoir Operational } \\
\text { Control Policy }\end{array}$ & $\begin{array}{l}\text { 1. Industry Evalu- } \\
\text { ation } \\
\text { 2. Guidelines and } \\
\text { Procedures }\end{array}$ \\
\hline
\end{tabular}


Subsidence monitoring via direct monitoring instrumentation (Research Category 3), subsidence prediction via accurate subsidence models (Research Category 8), and the consequences of subsidence as determined by environmental and economic effects studies (Research Category 4) lead to development of a balanced reservoir operational control policy (Research Category 9), the program's ultimate objective. Hence the program is integrated in a goal-oriented direction. Each Research Category is dependent upon at least one other Category. In addition, the program is constructed so that feedback loops are permitted. For example, new findings by indirect techniques to estimate deformation at depth, subsidence models, or laboratory testing can affect the physical theory of subsidence processes. If necessary, the physical theory can be modified to account for the new results. This feedback mechanism enables improved indirect techniques, subsidence models, and laboratory testing to result. The research plan, through annual program reviews, makes allowance for such feedback effects. The major interfaces among projects belonging to the Research Categories are given in Appendix B. 


\section{RESEARCH SCHEDULE AND MILESTONES}

The individual research projects are scheduled in Figure 3-1. The schedule was prepared assuming the work would start during the third quarter of FY 1977 and the research objectives would be reached by the end of FY 1980. The length of each bar on the schedule is an estimate of the total time span to complete the research project. It does not indicate the level of effort. 


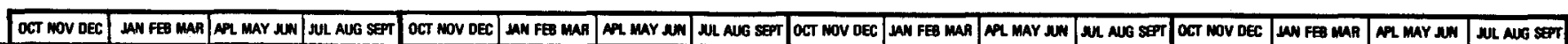

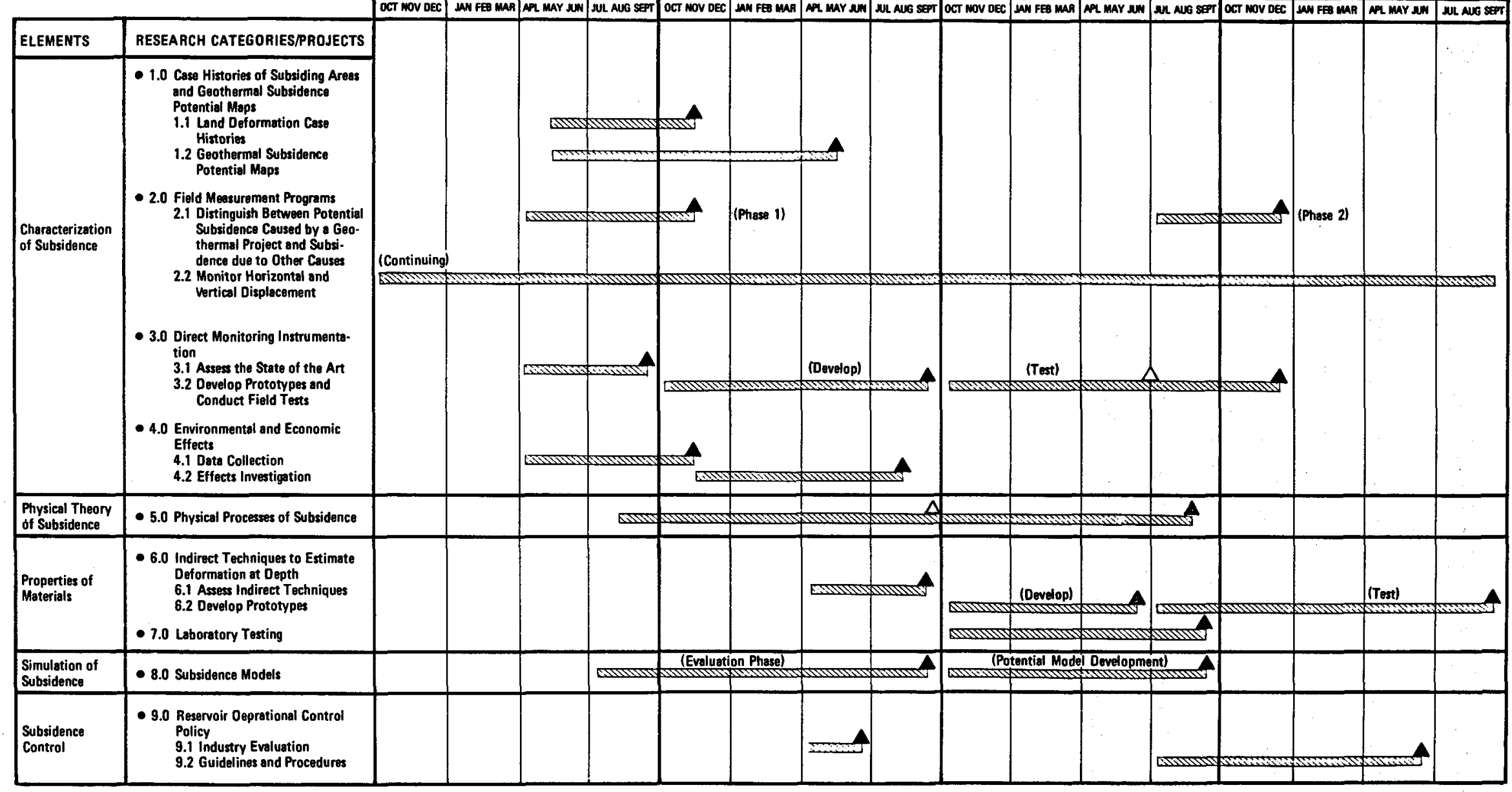

XBL 774-8429

Figure 3-1. General Reserach Program Plan Schedule. $\triangle$ Interim Report/Results; $\triangle$ Final Reports/Results 


\section{APPENDIX A. \\ RESEARCH PROGRAM PLAN DEVELOPMENT}

This document, which defines the Geothermal Subsidence Research Program Plan, was developed using two teams. The first was the program planning team. This team conducted an interdisciplinary analysis of the current state of research within a selected category of topics. 1 The program planning team then assessed the need for additional research and provided written research programs for review by the other program planning team members. An independent review team reviewed and commented on the overall program and the draft research projects at an interim workshop. Based on comments from the review team, the planning team revised the plan. During a second meeting, a final review was conducted and assessments were provided from the review-team members. These assessments were then incorporated into the plan. The interaction of the teams is summarized in Figure $A-1$.

Description of Program Plan Development

The following task descriptions provide a detailed record of the process used to develop this research program plan.

Task 1 Organize Planning Team.

The program planning team was composed of key research personnel within LBL, including the project manager, supplemented by appropriate technical experience. The planning team met formally at four different times and numerous informal discussions were conducted. Each planning 
team member was assigned a research category according to his expertise. Each team member was responsible for preparing descriptions of research needs within his assigned category. Each planning team member presented his recommendations for subsidence research at a formal oral presentation before the review team.

The planning team organization is shown in Figure A-2. The organization was based on a comparison of the technical expertise of team members to the research categories. In a group session, each individual indicated the area of his technical capabilities and interests. On the basis of their major technical strengths, individuals were selected to plan the research in specific categories. They were assisted by other team members as appropriate.

Task 2 Conduct Literature Research.

Based on the expertise of the individual planning team members, critical literature in each research category was reviewed. This review was assisted by the development of an LBL geothermal subsidence library, which was compiled with contractor assistance. The library consists of over 600 documents catalogued by author and according to the research categories in this plan. This library will be made available to future contractors as assistance in reviewing critical subsidence literature in their categories of interest.

Task 3 Preliminary Evaluation of Research Status and Requirements. Each member of the planning team independently performed the necessary evaluation of both status and requirements for his categories. 
MAJOR SCHEDULE EVENTS:

- Planning Team

- Draft Program

- Revise Draft

- Finalize (as necessary)

- Review Team

- Workshops

- Comments

- Review

- Present to ERDA

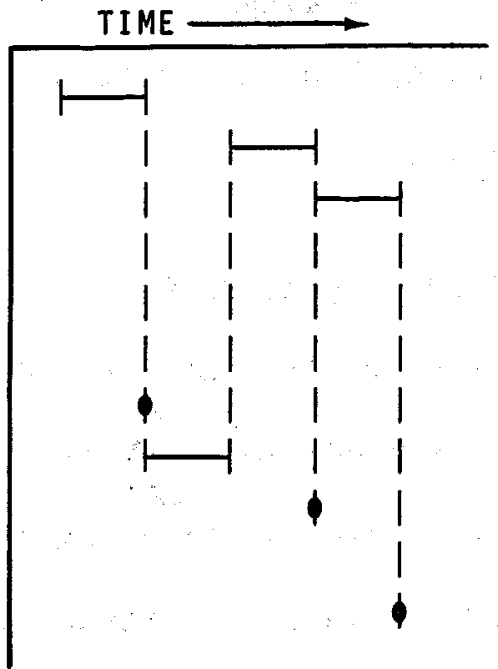

XBL 774-8424

Figure A-1. Program Plan Development Schedule. $\bullet=$ Major meetings.

\begin{tabular}{|c|c|c|c|c|c|}
\hline \multirow[b]{2}{*}{ PLANNING TEAM } & \multicolumn{5}{|c|}{ RESEARCH CATEGORIES } \\
\hline & 1 & 2 & 3 & 4 & ETC. \\
\hline Names & $d c^{*}$ & & $\sigma$ & & \\
\hline & & r & 1 & & \\
\hline & $\checkmark$ & & $\checkmark$ & $d c^{*}$ & \\
\hline & & $d c^{\star}$ & & & \\
\hline & $\theta$ & 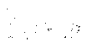 & 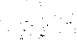 & $\sigma$ & \\
\hline & & $\phi$ & $d *$ & 1 & \\
\hline
\end{tabular}

KEY SUPPORT PERSONNEL

\begin{tabular}{|c|c|c|c|c|c|c|}
\hline \multicolumn{1}{|c|}{ Names } & $\checkmark$ & & & $\checkmark$ & \\
\hline & & $\diamond$ & $\checkmark$ & & & \\
\hline & & & & & & \\
\hline & & & $\checkmark$ & $\checkmark$ & & \\
\hline
\end{tabular}

XBL 774-8425

Figure A-2. Program Planning Team Organization (example), $\sqrt{ }$ Capability/ Interest; 0 Professional Strength; * Responsible (Text/Presentation); c Contact. 
However, at the team meetings, the progress on each category was reviewed by the full team, and suggestions were made as to additional concepts to be considered.

Task 4 Develop Program Plan.

A preliminary draft of the proposed research projects within each category was developed by the planning team and incorporated into a single document, which was issued several weeks before the first review workshop. In developing a research project, the planning team followed an outline provided by the project manager:

- Background

- Statement of Problem

- Discussion of Solution

- Research Objective

- Research Project Tasks

- Priority

- Schedule and Level of Effort Estimates

- Summary of Products and Milestones

This arrangement follows the steps a planning team member would typically follow, starting with a general review of the research background and finishing with the research projects. This concept could be thought of as a funnel; start with a wide overview and narrow down to specifics. In some cases it was possible to complete the outline; for other projects only part of the outline was completed before the first workshop. 
Task 5 Organize Review Team.

Based on a review of over 40 individuals, which included assessments of their education, professional background, location, affilitation, and expertise in the research categories, review-team members were selected and asked to participate. The resulting review team consisted of industrial, academic, and government personnel identified in Figure $\mathrm{A}-3$.

\section{Task 6 Convene Workshop.}

Prior to a two-day workshop, copies of the draft research programs were sent to the review team. During the first day of the workshop, each planning team member made an oral presentation justifying the proposed research project for which he was responsible. The second day of the workshop was taken up by a closed session of the review team in which the research categories and proposed projects were evaluated.

\section{Task 7 Review-Team Recommendations.}

As a result of the workshop, each review-team member was assigned two to four research categories for comment based on his interest. During the selection by the review-team members, an effort was made to have at least two members commenting separately on any given category. The recommendations were mailed directly to the review-team chairman, who incorporated all of the comments into one statement representing the combined view of the review team. This review-team position paper was then mailed back to the members for review. 


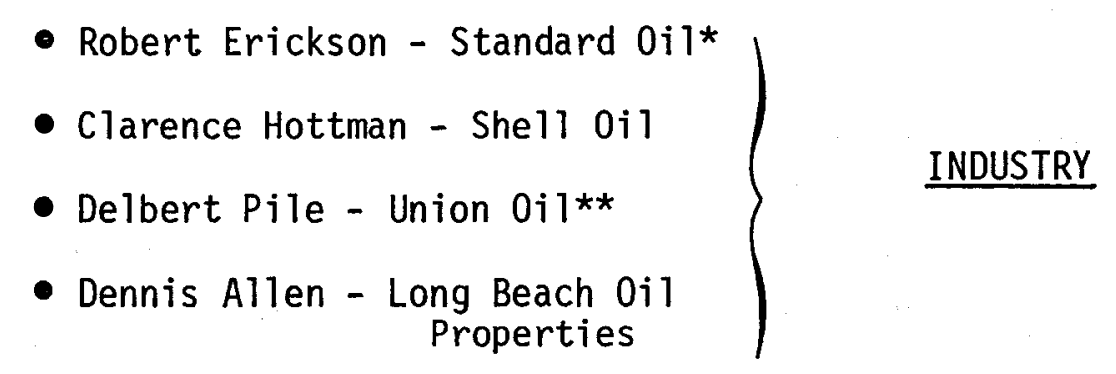

- Ronald Scott - California Institute of Technology

- Paul Jones - Louisiana State University

ACADEMIC

- Denis Norton - University of Arizona

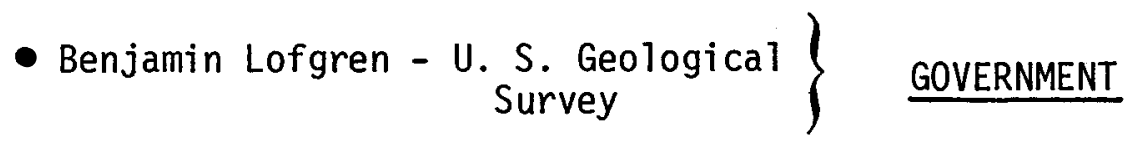

XBL 774-8426

Figure A-3. Subsidence Research Task Force. * Chairman. ** B. (Don) Outmans of Union Oil Provided Assessment of Laboratory Research Projects. 
Task 8 Incorporate Recommendations.

Based on the review-team position paper, the draft research program plan was revised and reissued by the Laboratory to the review team.

\section{Task 9 Convene Second Workshop}

The review team met for a second time to assess the comments on the draft research program. The review-team jointly drafted an acceptance letter, which was issued by the review-team chairman to LBL. The acceptance letter is reproduced in Figure A-4.

Task 10 Publish the Program Plan.

The above task descriptions summarize the major steps taken in the preparation of this program plan. There are a number of other ways to develop a research program plan. However, an approach similar to the one outlined above provides a balanced plan. such an approach assures that varied technical interests are served. similarly, the nontechnical concerns can be considered in the planning process. 
Dear Mr. Simkin:

On December 20, 1976, the following Task Force members met in Berkeley, CA, with LBL and ERDA representatives to discuss the final draft of LBL's geothermal subsidence research program plan:
H. (Don) Outmans, Union Oil Company of California
Delbert Pile, Union 011 Company of California
R. C. Erickson, Chevron U.S.A. Inc.
Dennis Allen, City of Long Beach
Ben Lofgren, U.S. Geological Survey
Paul H. Jones, Loulsiana State University
Dennis Norton, University of Arizona

Task Force members not in attendance but who have supplied input are:

Clarence Hottman, Shell oil

R. F. Scott, California Institute of Technology

The purpose of this meeting was to obtain the Task Force's assessment of this plan. After reviewing the contents of the report, the Task Force takes great pleasure in informing LBL that they find the plan to be acceptable and recommend that it be implemented as outlined in Section 4. The only exception is the recommendation that work in Research Category No. 5.3 should be deleted and the effort for this category in FY 1978 be added to Research Category No. 7. Before making specific comments about the plan, the Task Force wishes to commend the personnel of LBL who prepared the plan for constructing a document that is of high quality and completeness. The Task Force offers the following comments, suggestions and recommendations concerning the geothermal subsidence research program plan dated December 10, 1976:

1. It is suggested that the introduction be reworded to reflect that the subsidence problem needs to be placed in proper perspective so that ongoing operations and projects are not held up based upon the prediction of what might be a relatively rare event. The Task Force members are concerned that subsidence could become a sensitive issue with various permitting agencies if the 
nature of the problem 18 not adequately circumscribed.

2. The Task Force recognizes the need and value for the suggested budget program proposed by LBL but wishes to refrain from comenting on the proposed funding level.

3. If the research program is inftiated, It should be reviewed and reassessed on an annual basis by a Task Force group similar in composition to this one.

4. A statement covering research on induced selsmictity during geothermal operations could be Included in the report. Task Force members thought that this subject could either be taken up at the option of the project leaders or even be recommended for consideration by the group who will be handling geothermal reservoir research.

5. It was agreed by the members of the Task Force that their names and affiliation could be cited in the final report If LBL so desired.

6. The Task Force agrees with the LBL proposal that the final document should be issued as a public item under the LBL label and should not Include the estimated budget moneys.

7. It is the understanding of the Task Force members that this group w111 no longer continue to function or follow the progress of the research as presently organized. However, should the need arise, Individual members expressed an interest and willingness to assist LBL on an Individual basis if LBL wish to make such a request.

The members of the Task Force wish to thank the staff of the Lawrence Berkeley Laboratory for the opportunity to participate in the formulation of the proposed geothermal subsidence research program plan.

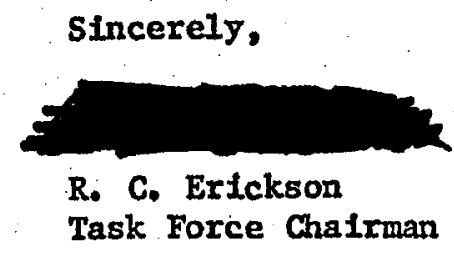




\section{REFERENCE}

1. "Status of Present Knowledge and Needs for Additional Research on Compaction of Aquifer Systems," Joseph F. Poland, in Land Subsidence, Proceedings of the Tokyo Symposium, September 1969, Vol. 1, pp. 11-20; published by the International Association of Scientific Hydrology. 


\section{APPENDIX B. RESEARCH CATEGORIES}

\section{RESEARCH CATEGORY 1}

\section{Case Histories of Subsiding Areas and Geothermal Subsidence Potential Maps}

Project 1 is the documentation of case histories to be used for evaluating potential subsidence at geothermal sites. Project 2 is the development of geothermal subsidence potential maps.

PROJECT 1 - SUBSIDENCE CASE HISTORIES

\section{Background}

In a number of projects the extraction of fluids from the ground has caused geological deformations up to and including the land surface. Documentation about these deformations ranges from nonexistant to extremely accurate historical recordings. Some of these data, however, are not readily accessible.

While most land deformation has been due to extraction and injection of hydrocarbons or groundwater, useful analogies may be drawn for the production of geothermal fluids. A major difference may be the longterm, high-temperature effect on the fluids and the reservoir. Hydrothermal alteration of sedimentary beds may have cemented the materials. Thus their response to manmade stress may be similar to that of a fractured-rock reservoir.

In some cases, deep extraction of fluids has produced little or no subsidence. A case history of the geologic and physical environments, 
the stress history, and the response or lack of response at land surface, in comparison to potential geothermal systems would produce useful information.

\section{Statement of the Problem}

There is a lack of well-documented case-history studies of subsidence applicable to geothermal systems.

\section{Discussion of a Solution}

Published information on areas of subsidence should be summarized to produce condensed case histories. For areas having geological and physical environments most pertinent to geothermal exploitation, detailed case histories should be prepared. This might require personal interviews and correspondence to obtain as complete a documentation as practical. Such case histories should define a range of subsidence for reservoirs in different geologic settings (e.g., granular sedimentary deposits, volcanic rocks, or fractured metamorphic rocks). Documentation of this kind is a prerequisite for the preparation of subsidence potential maps; refer to Research Category 1, Project 2.

\section{Research Objective}

The objective of documenting case histories is supplying information to individuals concerned with the subsidence potential of geothermal activities. Such individuals include: 
- Developer/Builder

- Government policy maker/regulator

- Reservoir engineer

- Mathematical modeler

\section{Research Project Tasks}

The research profect described (see also Figure B-1) indicates the major tasks. These tasks represent only an outline of the steps needed to reach the objective. The detailed process is the responsibility of the research contractor.

Task 1 Select Case Histories.

Various aspects of case histories should be considered, such as:

- Types of fluias involved.

- Geology of the overburden and reservoir.

- Production history.

- Method of operation or production.

- Control procedures, which may not include injection.

- Techniques used to make measurements of deformation, results obtained, and appraisal of accuracy of the data.

\section{Task 2 Format Case History.}

The format for documenting case histories should be prepared early in the planning process. This may be done in parallel with Task 1. It might include descriptions of geological settings and a summary of the operations used throughout the reservoir production ilfe. 
The format might also include a section on indicators of subsidence and their effect in field situations.

Factors that influence subsidence include reservoir properties and geometry, overburden thickness and composition, and faults and fracture systems. 1 (See Project 2 of this category for further details.)

The information might be formatted as computer input to validate existing or future subsidence models.

\section{Task 3 Screen Subsidence Areas}

The applicability of case histories to geothermal-related subsidence should be considered.

Furthermore, consideration should be given to the availability of data. In some instances the information is published. In other cases, some data may be in process. ${ }^{2}$ on the other hand, private industry may represent a wide range of data availability. A sample of locations that could be considered for case history study may be found in Research Category 4.

Task 4 Obtain Case History Data.

Data should be obtained from published documents. However, these data should be supplemented by original records, notes, and field data of observers, as well as personal interviews.

\section{Task 5 Document Case Histories.}

Case histories should be aimed at prospective users, including the developer or builder, the government policy maker, the geothermal 
reservoir engineer, and the mathematical modeler. The case histories serve to identify the conditions, both geologic and manmade, that are conducive to subsidence. They are essential for preparing maps of subsidence potential, either as input to models or for use in a more qualitative form.

\section{Priority and Interfaces}

Documenting pertinent case histories has a high priority. Case histories would supply information to the following research categories:

1 (Develop Subsidence Potential Maps)

4 (Environmental and Economic Effects)

8 (Evaluate Existing Mathematical Models)

9 (Evaluate Operating Policies)

\section{Product and Milestones}

The product of this research program would be written case histories with specific information for computer usage where available.

One milestone would be Task 3 , recommendation of screened subsidence areas for case study. The final milestone would be the publication of documented case histories.

PROJECT 2 GEOTHERMAL SUBSIDENCE POTENTIAL MAPS

\section{Need for Research}

The amount of subsidence that may occur in any geothermal area as a result of fluid production depends on many factors. In the early phases of development, limited field information and the lack of production 
history may preclude the accurate prediction of potential subsidence. Thus, it would be desirable to have initial evaluations of the subsidence potential in selected areas based on some defined guidelines of assessment. This would be similar to the concept of seismic risk maps. The defined standards would be based chiefly on geologic characteristics and the anticipated manmade stress.

\section{Statement of the Problem}

There does not currently exist a definitive means for estimating subsidence potential during early stages of geothermal site development. Discussion of a Solution

Based on factors influencing deformation in geothermal production areas, it should be possible to establish guidelines of evaluation and produce maps. These maps would indicate a range of subsidence potential for areas that may undergo geothermal development. This process may not accurately define the severity at any given site. But such maps would be useful in the early stages of development for indicating an overview of the subsidence potential expected.

\section{Research Objectives}

The objectives are the development of geological guidelines for estimating subsidence related to geothermal production. The guidelines will be applied to develop subsidence potential maps. 
Research Project Tasks

The following tasks (see also Figure B-2) represent the steps to be taken in reaching the stated objective. The actual procedures for conducting the research program are the responsibility of the research contractor.

Task 1 Develop Evaluation Guidelines.

The following list represents evaluation guidelines that may be either quantitative or qualitative. The contractor will determine what guidelines are available for a particular area. He will then apply those guidelines in developing the subsidence potential maps.

Structural Geology--Geologic factors that might influence potential subsidence within a given area include:

- Rock type and stratification.

- Folding.

- Faulting.

- Fracturing.

- Regional stresses.

Reservoir Materials--Various properties of reservoir material may be considered, such as:

- Material type.

- Grain size and shape.

- Type and percent of interconnected pore space.

- Degree and history of consolidation.

- Amount of hydrothermal alteration and cementation. 


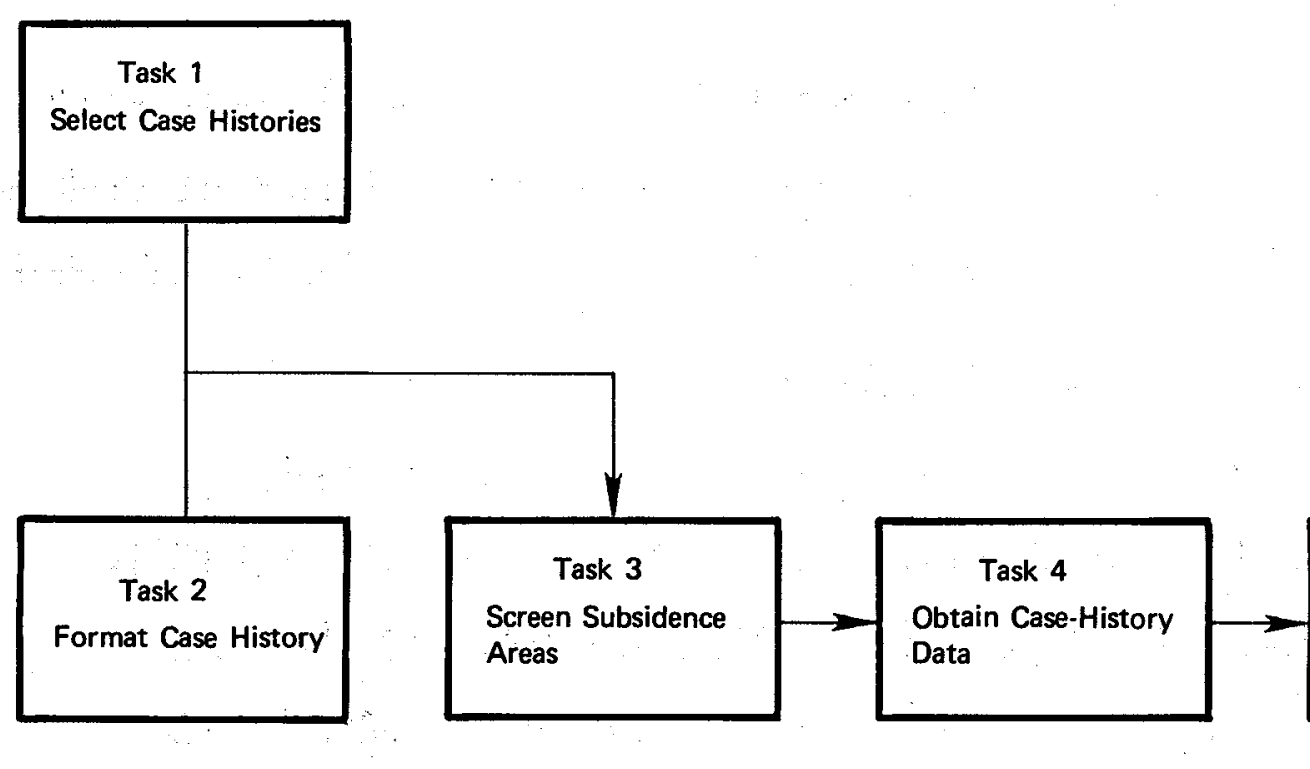

Task 5

Document Case

Histories

XBL 774-8427

Figure B-1. Develop Case History Studies.

PROJECT 2 - GEOTHERMAL SUBSIDENCE POTENTIAL MAPS

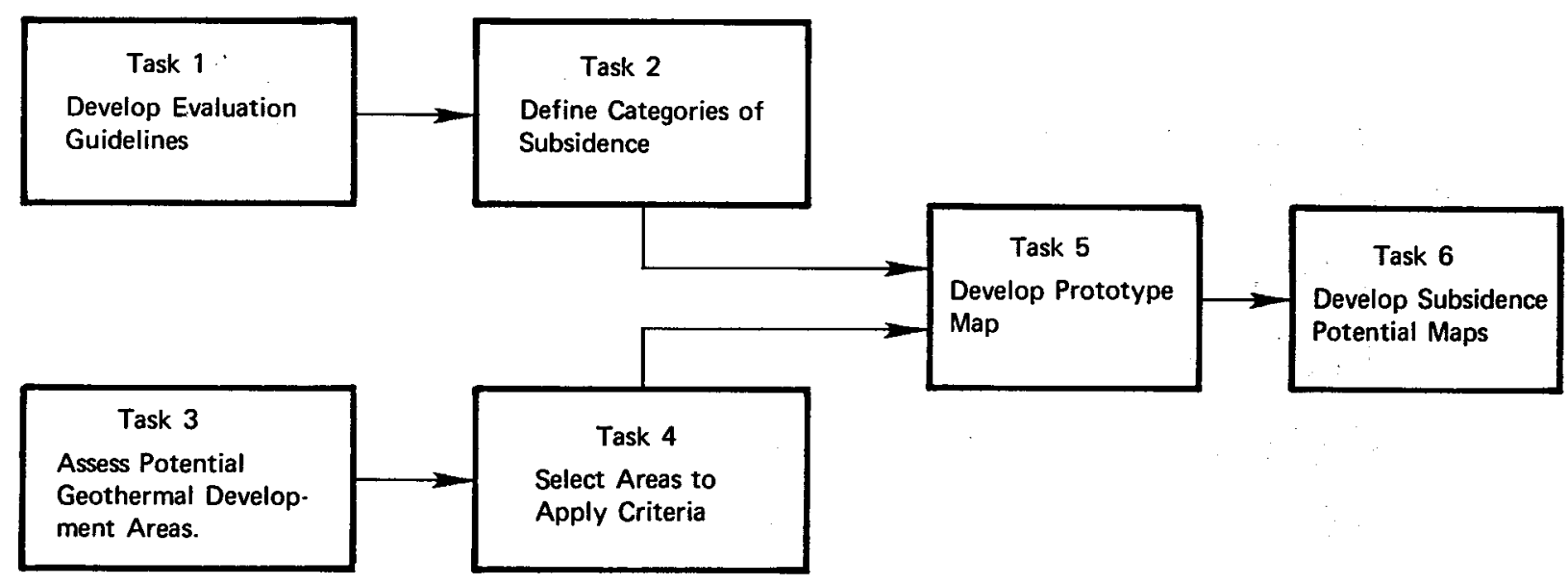

XBL 774-8428

Figure B-2. Develop Geothermal Subsidence Potential Maps. 
- Type and content of clay.

- Age of the materials.

- Degree of hydraulic communication.

Reservoir Geometry--The geometry of the reservoir may have influencing factors. Such aspects as extent and thickness should be considered.

Overburden--Influencing factors to be considered are thickness, competence, rock type, materials, density, and fracturing.

Fluid Characteristics--Such factors as fluid phase, temperature, pressure, and chemistry should be considered.

Geohydrology-The natural recharge system is one of the factors to be considered in assessing potential subsidence. Should there be some minimum standards for injection in an area to be developed, the effectiveness of this control should be considered in the subsidence potential.

Production Aspects--The rate and extent of fluid extraction may be considered and ranges of volumes may be assessed based on projected ultimate use. This can be either electrical power production and/or direct heat utilization. Changes in piezometric levels and pore pressure may also be considered, based on the rate of extraction in a given area.

Task 2 Define Categories of Subsidence.

Categories of potential subsidence should be defined, analogous to the three levels of ranking used for seismic maps. 
Task 3 Assess Potential Geothermal Development Areas.

Based on areas identified by ERDA, the production would be evaluated in specific time frames.

The smallest-scale map on which more than one risk pattern could be shown for a geothermal area (Known Geothermal Resource Area, or KGRA) would be about 1:500 000. If two or more zones of subsidence potential are to be shown, the scale probably should be $1: 250000$, depending on attainable detail.

Task 4 Select Areas to Apply Criteria.

The selection of areas would be based on timing, degree of use, need for data, and availability of information needed to support evaluations of criteria developed in Task 1. Tasks 3 and 4 may be conducted in parallel with Tasks 1 and 2 .

\section{Task 5 Develop Prototype Map}

Based on Tasks 1-4, a prototype map will be developed for evaluation prior to the development of maps in areas defined from Task 4.

\section{Task 6 Develop Subsidence Potential Maps.}

\section{Priority and Interfaces}

The priority for this research project indicates an early initiation.

This research will supply useful information to Categories 4 , 5 , and 8 . 
Summary of Product and Milestone

The major milestone would be the prototype map for review as

defined in Task 5 . The final product will be subsidence potential maps.

\section{REFERENCES}

1. The Analysis of Subsidence Associated with Geothermal Development, Vol. 1, Handbook, Chapter 5, Systams Control Inc. NSF/RAND 5139-1, 1976.

2. Casebook on Subsidence Due to Groundwater Withdrawal, an International review under the Chairmanship of J. F. Poland, United States Department of the Interior (in process). 


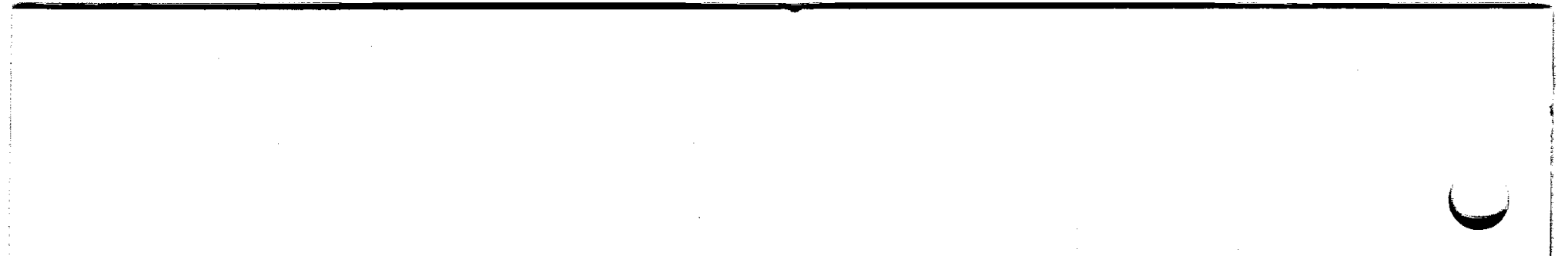




\title{
RESEARCH CATEGORY 2
}

\author{
Field Measurement Programs*
}

PROJECT 1--CRITERIA TO DISTINGUISE BETWEEN POTENTIAL SUBSIDENCE CAUSED BY A GEOTHERMAL PROJECT AND SUBSIDENCE DUE TO OTHER CAUSES

\section{Background}

Man-induced subsidence occurs in many regions, particularly where groundwater, oll, or gas has been extracted. Varying degrees of subsidence also result from the extraction of fluids used for geothermal applications. 1

A geothermal development program should include monitoring of horizontal and vertical subsidence at the surface and at depth before and during geothermal-related activities. It should differentiate between subsidence caused by geothermal operations and that caused by other man-induced activities, or occurring naturally in the region.

A simple example illustrates one concept that might distinguish between the causes of subsidence. It is assumed that a net of geodetic benchmarks and extensometers is installed in 1977 in a geothermal area. The monitoring starts the same year and typical data for the 1977-1985 period are provided. Large-scale fluid production is assumed to start in 1982 .

Figures $\mathrm{B}-3$ and $\mathrm{B}-4$ show the vertical ground movement recorded for the periods 1977-1981 and 1977-1985, respectively. Figure B-3 shows that the movement tends to increase uniformly towards the south * Announced in the Commerce Business Daily, September 13, 1976 as Category 7. 


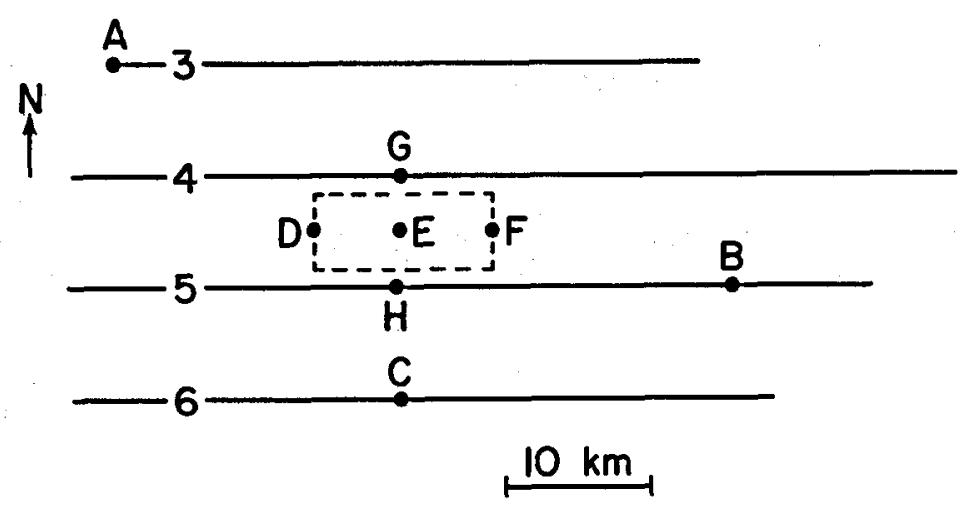

XBL773-548

Figure B-3. Bypothetical Example of Vertical Ground Movement (1977-1981) $:-5-=$ lines of equal vertical ground movement (mm) (1977-1981; production is expected to start in 1982): $\mathrm{B}$ = benchmark (station).

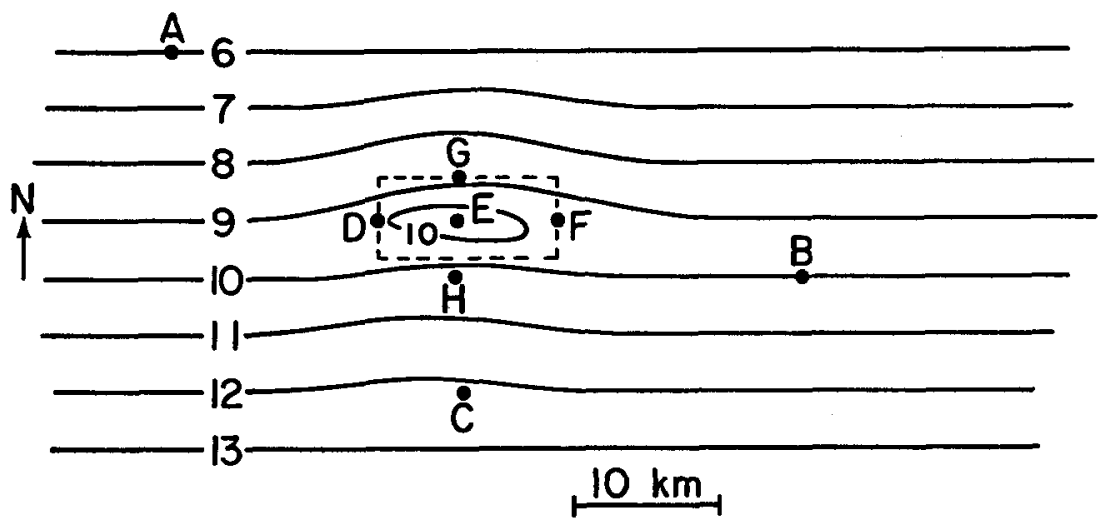

XBL $773-549$

Figure B-4. Hypothetical Example of Vertical Ground Movement (1977-1985) $-8-=$ lines of equal vertical ground movement (mm) 1977-1985 production started in 1982): $\mathrm{B}$ = benchmark (station) . 
before the exploitation of the geothermal fleld begins. Figure B-4 illustrates how the lines of equal vertical ground movement have been distorted around the field after large-scale fluid production starts (1982). Figure B-5 depicts the evolution of the ground movement with time. The rate of deformation is uniform at stations $A$ and $B$, which are distant from the geothermal field. Stations within the field such as E clearly show a change of slope after the start of fluid production.

Figure B-6 illustrates the horizontal ground movement measured during the 1977-1985 period. Stations A, B, and C show a regional deformation towards the south, but the stations near or within the geothermal field show a different pattern. This pattern results from the superposition of the area related to the development of the geothermal field over the regional field.

Changes of depth could also be measured, assuming instruments are developed to withstand the high temperatures and depths of geothermal fields. (See Category 3 for the research being conducted to develop such instruments.) Figure B-7 depicts a nest of extensometers located within the geothermal field at station $E$. These instruments measure the vertical deformation occurring between the surface and different depths. In Figure B-8 the deformation history registered at the different extensometers is shown. The graph indicates that the compaction of the reservoir and lower caprock rapidly increases after 1982, the year when large-scale production started. 


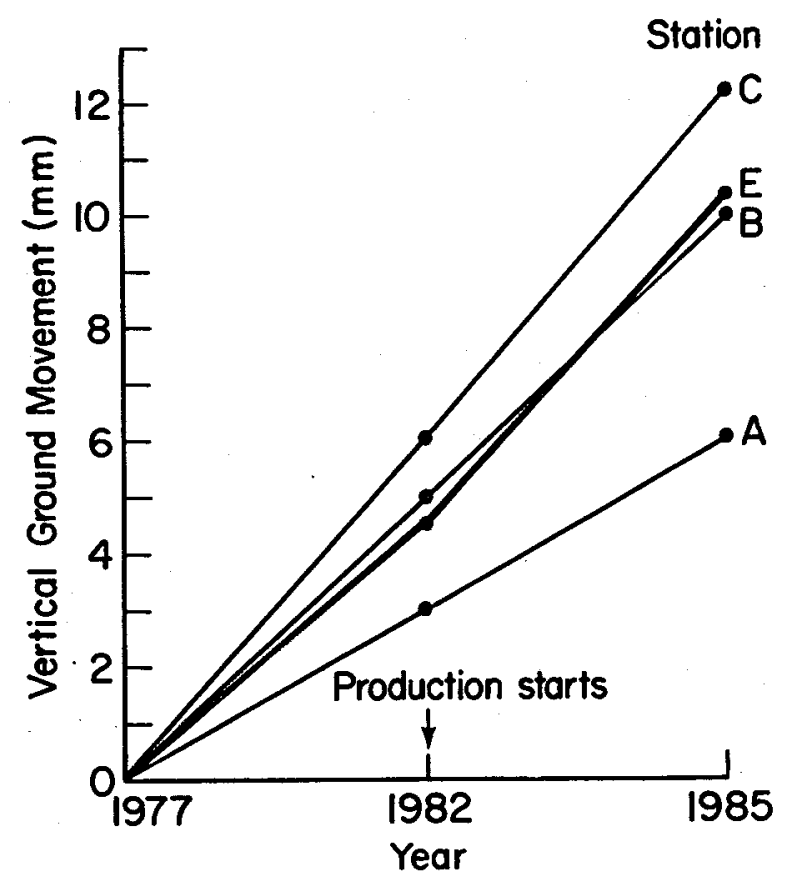

XBL773-550

Figure B-5. Hypothetical Example of Vertical Ground Movement (1977-1985).

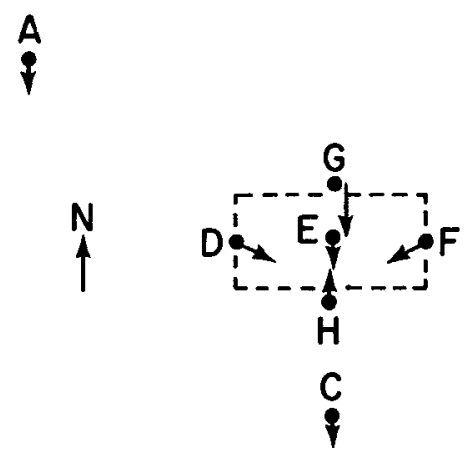

\section{B}

$10 \mathrm{~km}$

XBLT73-551

Figure B-6. Hypothetical Example of Hor izontal Ground Movement

(1977-1985) $\longrightarrow=$ vector indicating horizontal displacement (1977-1985), scale of vector $1: 1 ; i=$ geothermal field (largescale geothermal fluid production started in 1982); $D=$ benchmark (station). 


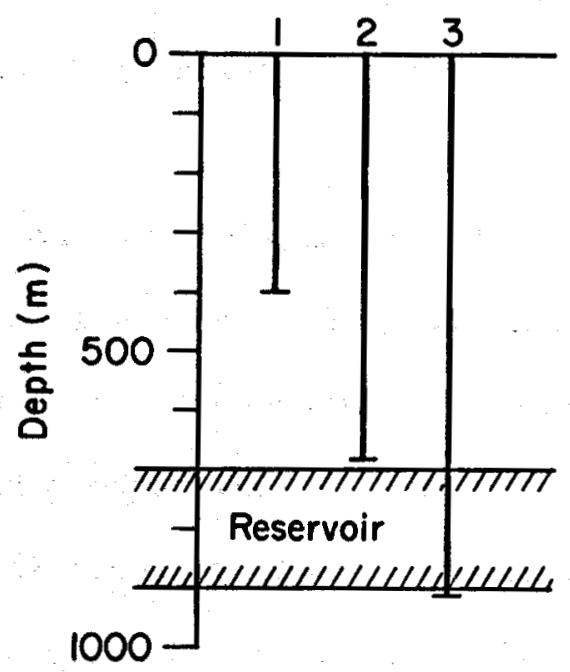

XBL773-552

Figure B-7. Nest of Extensometers Located at Station E. Extensometer 1 measures compaction between $0-400 \mathrm{~m}$; extensometer 2 measures compaction between $0-690 \mathrm{~m}$; extensometer 3 measures compaction between $0-910 \mathrm{~m}$.

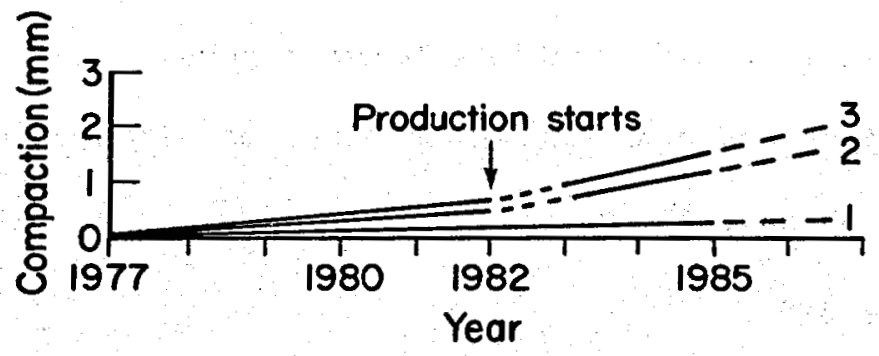

XBL773-553

Figure B-8. Hypothetical Example of Vertical Compaction measured at Station $E$ (1977-1985); numbers 1,2 , and 3 on the graph lines refer to the extensometer numbers. 
This example provides information relative to the production of geothermal fluids and the effect on vertical and horizontal ground displacements.

In a field situation, the explanations may not be so simple. The monitoring program will need careful planning, such as location of various stations and monitoring instruments, frequency of measurement, precision requirements, etc. In addition, methods have to be developed to interpret the data,considering geology, tectonic activity of the region, local extraction of groundwater and hydrocarbons, previous history of ground deformation of the area, etc.

To date, for geothermal areas, no guidelines for relevant fielddata acquisition and analysis are available. Recently some systematic geodetic measurements have been described for the United States ${ }^{2,3}$ and New zealand. 1,4

A geothermal development program needs guidelines to monitor horizontal and vertical subsidence at the surface and at depth. These guidelines must differentiate between subsidence caused by a geothermal project and that caused by other man-induced or natural subsidence. Such guidelines would assist in planning site-specific monitoring programs.

\section{Statement of the Problem}

The geologic setting of most geothermal systems is such that natural subsidence may occur without geothermal exploitation. Bydrothermal (water and vapor-dominated) geothermal systems tend to 
be located in tectonically active regions or near faults that still may be active. Geopressured systems tend to be located in basins where rapid sedimentation has resulted in thick columns of unconsolidated and undercompacted sediments. Both of these settings can exhibit noticeable natural subsidence.

The following are characteristic of geothermal sites likely to be encountered in a monitoring program:

- Basin and range structures (e.g., Nevada).

- Rift valley structures (e.g.., Imperial Valley and Rio Grande graben).

- volcanic calderas (e.g., Valles Caldera).

- Eighly deformed and metamorphosed regions (e.g., the Geysers).

- Sedimentary basins with associated geopressured systems (e.g., Northern Gulf of Mexico Basin).

The topography of these settings may require different methods for subsidence monitoring.

\section{Discussion of a Solution}

Very little has been done to distinguish different causes of subsidence. 5 Thus, guidelines should be developed to obtain data that could be used to establish the amount of movement directly related to geothermal fluid production. These guidelines should consider the geologic structure, stratigraphy and seismicity of the area, as well as the existing and proposed groundwater, gas, and oil developments. The 
guidelines should also consider, if available, any known natural grounddeformation characteristics of the region and any manmade deformation of nearby fluid-producing fields.

Techniques must also be developed to interpret the collected subsidence data. By comparing subsidence at different stations, and observing where in the stratigraphic column subsidence occurs, it may be possible to measure the contribution of a geothermal development to natural subsidence. Interpretation of the data must consider the geologic characteristics and previous deformation history of the area. The amount of and the depth from which groundwater, oil, gas, and geothermal fluids are produced must also be considered.

Guidelines will be prepared for use in planning a monitoring program. The program will include gathering baseline data prior to operation,periodically or continuously during the operating period, and for a specified time thereafter. Guidelines may be prepared for specific geologic settings, if these settings require special techniques and data interpretation.

Research Objective

Prepare a guidelines manual for developers and planners. This manual will be used to develop programs to monitor subsidence associated with geothermal operations. The guidelines will seek to distinguish between causes of horizontal and vertical displacements at the surface and movement below the surface. 
Research Project Tasks

The research will focus on preparing a manual containing guidelines for planning, obtaining, and interpreting:

- Pre-operational baseline.

- Operational monitoring.

- Post-operational monitoring.

Many survey networks already exist. Past history on existing networks may enhance the monitoring networks of an area and should be used where appropriate. For example, the major leveling nets of the National Geodetic Survey along the Gulf Coast may serve as baseline background and reference benchmarks for future surveys.

Table B-I shows the geodetic network and responsible agency in eight selected geothermal areas.

Figure B-9 indicates the suggested outline of activities necessary to prepare guidelines. The research will be accomplished as the result of two research phases. Phase 1 will develop guidelines for field investigations and monitoring programs based on available surface measurement instrumentation. Phase 2 will revise the guidelines based on the availability of future instruments to measure below the surface (see Research Category 3 ).

Task 1 Determine Information Requirements.

Information requirements will be developed for defining the pre-operational shape of the land surface. Information requirements will also be established for monitoring subsidence over the life of 
Table B-I. Geodetic networks in eight geothermal areas.*

\begin{tabular}{|c|c|c|c|c|}
\hline & \multicolumn{2}{|c|}{ Vertical Net } & \multicolumn{2}{|c|}{ Horizontal Net } \\
\hline & Status & Agency & Status & Agency \\
\hline Geysers, Calif. & $\mathbf{E}$ & USGS & $\mathbf{E}$ & USGS \\
\hline Long Valley, Calif. & $\mathbf{E}$ & USGS & $\mathbf{E}$ & USGS \\
\hline Coso Hot Springs, Calif. & $\mathbf{E}$ & USGS & $\mathbf{P}$ & USGS \\
\hline Eeber | & $\mathbf{E}$ & $\mathbf{I}$ & $\mathbf{E}$ & USGS \\
\hline \begin{tabular}{l|c} 
Brawley & Imperial Valley, \\
Buttes & Calif.
\end{tabular} & $\begin{array}{l}\mathbf{E} \\
\mathbf{E}\end{array}$ & $\begin{array}{l}\text { I } \\
\text { I }\end{array}$ & $\begin{array}{l}E \\
E\end{array}$ & $\begin{array}{l}\text { USGS } \\
\text { USGS }\end{array}$ \\
\hline Raft River, Idaho & $\mathbf{E}$ & USGS & $\mathbf{E}$ & USGS \\
\hline Roosevelt Hot Springs, Utah & $\mathbf{P}$ & USGS & $\mathbf{P}$ & USGS \\
\hline
\end{tabular}

* = Areas in the Gulf Coast geopressured zone are not shown.

$E$ = Established.

$P=$ Partially established.

$I$ = Interagency, which includes the following:

National Geodetic Service

Imperial County

Imperial Irrigation District

U. S. Bureau of Reclamation

California Division of Highways

U. S. Geological Survey

Note: The Imperial County Survey at El Centro is the respository of the vertical net data. 
TASK 1 Determine Information Requirements

TASK 2 Develop Information Collection Methods

TASK 3 Interpret the Data

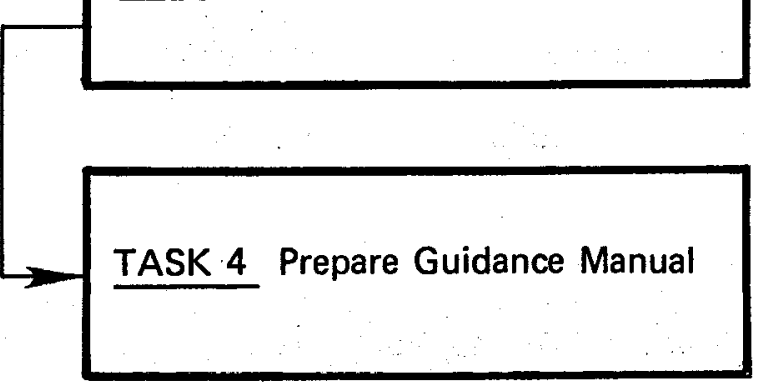

Figure B-9. General Schedule: Develop Guidelines for Monitoring Potential Ground Deformation Associated with Geothermal Development.

XBL 774-8430 
the geothermal project, including the recommended precision of the various measurements.

Task 2 Develop Information Collection Methods.

Instrumentation and techniques will be recommended for acquiring information on the number of locations and precision necessary for performing interpretive analyses. The following questions should be answered:

- How and where to set up a network of benchmarks of first- and second-order leveling and trilateration surveys?

- What precision is required, and how frequently should these surveys be made?

- How and where to install tiltmeters, extensometers, seismographs, and other monitoring instruments?

- What type of downhole measurements should be made?

- How frequently should tests be made?

\section{Task 3 Interpret the Data.}

These techniques would be based on:

- Comparison of local and regional subsidence patterns before, during, and after geothermal fluid production.

- The history of subsidence at stations within and away from geothermal fields measured before, during, and after geothermal fluid production. 
- The amount and rate of compaction occurring at different intervals of the geothermal reservoir and overburden before, during, and after geothermal fluid production.

- The correlation between rates of subsidence and geothermal fluid production.

Task 4 Prepare Guidance Manual.

A format for the prospective guidance manual will be developed. The format should be designed based on potential user requirements. Anticipated users will be planners (developers and public agencies) and field operating personnel.

\section{Priority}

In the United States, a number of geothermal fields in the next few years will start large-scale geothermal fluid production. The early acquisition of baseline data is crucial for differentiating the causes of ground displacements. Thus it is important to have the guidelines available soon. Therefore, high priority has been given to the development of these guidelines.

\section{Interfaces}

This research category interfaces with Category 8 , since it provides the procedures for obtaining fleld data to evaluate models. As feedback, these models could provide clues about what parameters should be monitored, where these measurements should be taken, and what precision would be required. 
It also interfaces with Category 9, since the collection of data will help develop reservoir management plans to minimize subsidence related to geothermal fluid production.

Since Research Category 2, Project 2, will use the guidelines developed in this research project, there exists a direct interface between them.

Summary of Product and Milestones

The product will be a monitoring guideline for geothermal field operators, recommending acquisition and interpretation of subsidence data. These data will be suitable for distinguishing between subsidence directly related to a geothermal project and that due to other causes. Milestones will include:

- Recommendation of information requirements

- Recommendation of format.

- Delivery of guidelines.

PROJECT 2. MONITOR HORIZONTAL AND VERTICAL DISPLACEMENT Background

Extremely accurate means exist for measuring horizontal distances and, to almost the same extent, vertical distances on the land surface. Instrumentation to measure horizontal and vertical displacements is summartzed below. 
Horizontal Displacement Monitoring (Land Surface)

(1) Trilateration, using line-of-sight distance measuring equipment (DME) .

(a) Geodolite, capable of 1 unit in $10^{7}$ units (laser) $30 \mathrm{~km}$.

(b) Electronic DME, capable of 2 units in $10^{6}$ (laser) $12 \mathrm{~km}$.

(c) Distance meter, capable of 1 unit in $10^{5}$, infrared, $3 \mathrm{~km}$.

Vertical Displacement Monitoring (Land Surface)

(1) Precise leveling by spirit level. (Refer to order and classification of precise levels in Table B-II.)

(2) Theodolites (trigonometric leveling) with retroreflective targets, giving vertical angles to 1 sec of arc or better.

(3) Tiltmeters, either mercury bubble or electronic; also binary (pendulum) type providing qualitative data.

(4) Tide gage records and float measurements on water bodies to define elevation change or tilting.

(5) Vertical extensometers, free pipe or anchored cable, anchored beneath the depth of any manmade compaction, to record displacement of land surface with respect to the depth benchmark.

(6) High-precision altimeters.

(7) Satellite or spacecraft ranging, and lunar ranging from ground to retroreflectors on the moon, all using laser techniques. Precise leveling, the most accurate method for measuring vertical displacement, has approximate costs as indicated in Table B-II. 
Table B-II. Typical costs of precise leveling (1976).

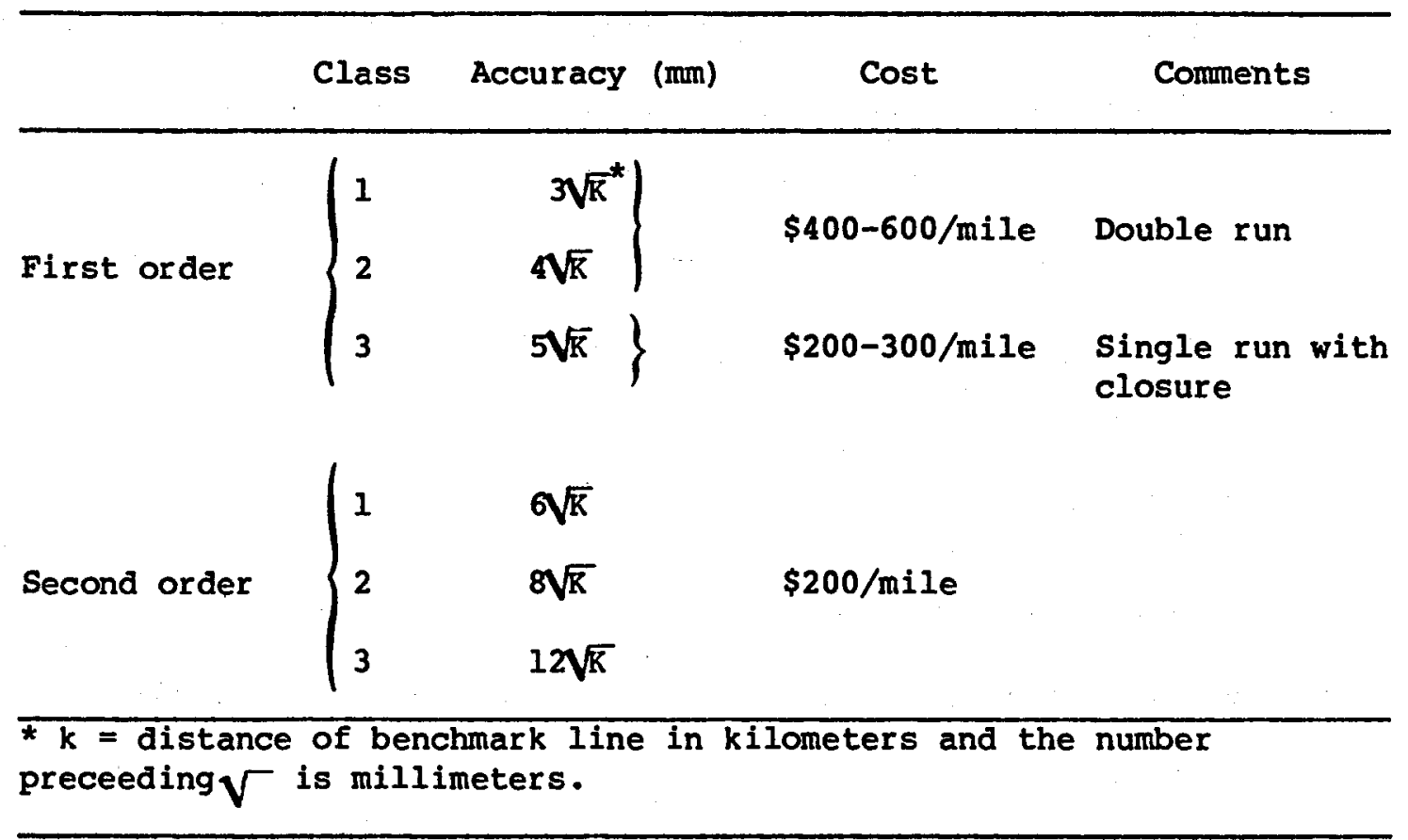


Assuming that 100 miles of benchmark first-order network is surveyed class 1, two times prior to geothermal development and once every 1.5 years thereafter for 20 years, the cost would be in excess of $\$ 600,000$. Should five geothermal areas undergo development, the total measurement costs would be about $\$ 3$ million spread over 20 years. Thus, efforts to reduce the cost of measurement would be desirable but could not be classified as being of critical importance.

\section{Statement of the Problem}

Only a limited number of accurate baseline surface measurements has been made in areas of potential geothermal development. Since the capability exists, baselines should be established by (1) installing a network of benchmarks, (2) establishing the elevation of the benchmarks by precise leveling, and (3) establishing the horizontal position of selected benchmarks for trilateration (DME). It is important to survey the benchmarks and their elevations prior to development. An attempt should also be made to assess what is occurring both naturally and by man-induced activities (refer to Project 1 in this Category). The extent of current baseline layout in eight geothermal areas is listed in Table $B-I$.

\section{Discussion of a Solution}

Based on an evaluation of the areas requiring baseline data, conduct a field-measurement program in prospective areas. Such measurements. 
could use the techniques developed by Project 1 in this Category. It may also use new instruments when available from Research Category 3.

Research Objective

The major objective of the field measurements is to provide at appropriate locations the present and future elevations and orientation of the land surface as baseline data.

\section{Research Project Tasks}

Refer to Figure B-10 for a summary of the tasks.

Task 1 Identify Areas for Field-Surface Measurements.

Using, as a starting point, the Assessment of Geothermal

Resource of the United States (Circular 726) by the 0 . S. Department

of the Interior for ERDA, select areas that in the near future would

need baseline data.

Task 2 Screen Identified Areas.

Screen and rank areas to undergo measurement. Any effective selection process could be used, such as various forms of a matrix decision process.

Based on the comparison of areas, evaluate those of highest priority for starting or expanding baseline measurements. This task, as well as Task 1, may be accomplished either by or in conjunction with the division of Geothermal Energy. 


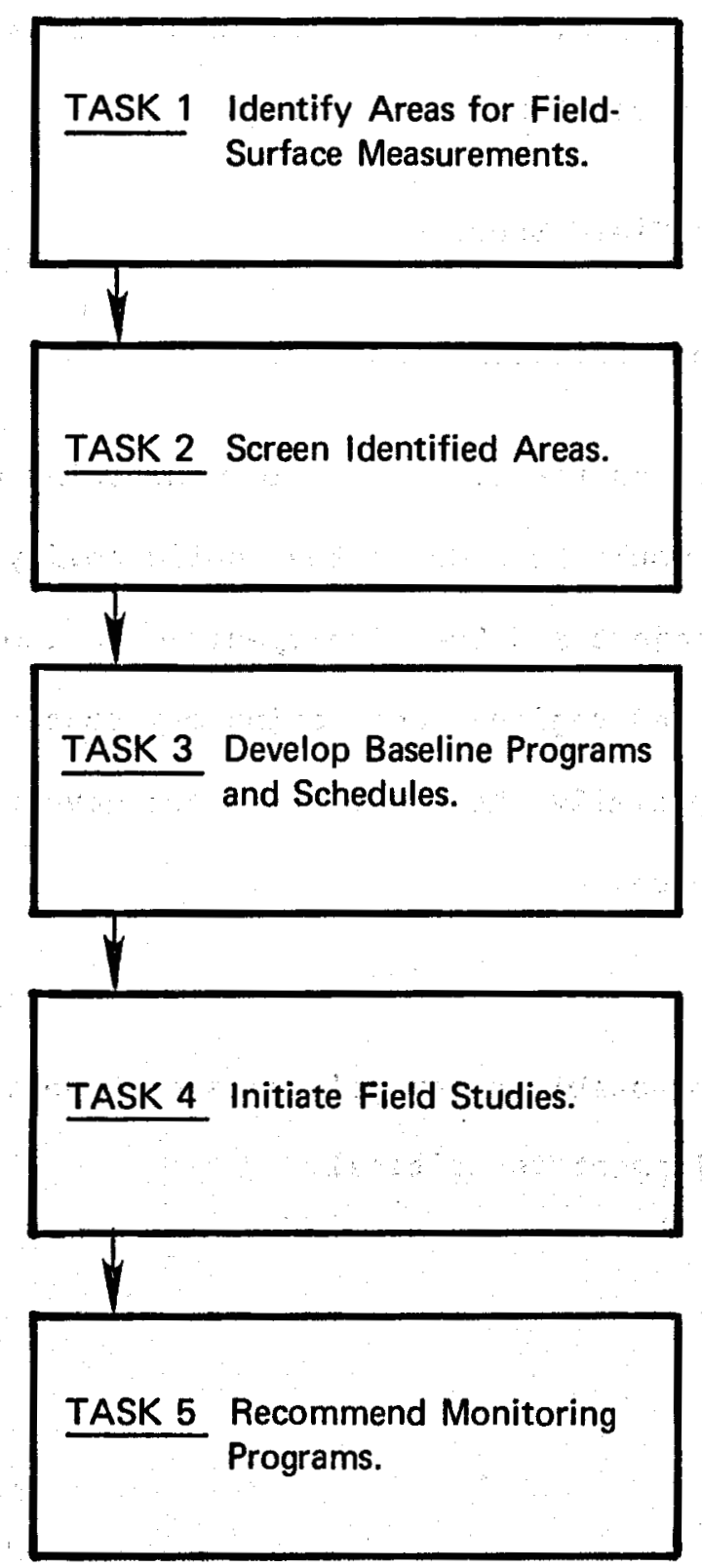

Figure B-10. General Schedule: Horizontal and Vertical Surface Measurement. XBL 774-8431 
Task 3 Develop Baseline Program and Schedules.

The development of monitoring methods in Project 1 of this Category should be considered. This will provide guidance in developing detailed area-specific programs. Such detailed programs may provide feedback in developing the monitoring methods.

\section{Task 4 Initiate Field Studies.}

Task 5 Recommend Monitoring Programs.

Recommendations for site-specific monitoring would be useful. The recommendations would be made to the public policy maker prior to approving the project and the site-specific monitoring specifications. Federally supported regional monitoring may continue after a project is approved, especially where more than one developer may be using the geothermal resource.

\section{$\underline{\text { Priority }}$}

The need to establish several years of baseline data prior to geothermal development is critical. 


\section{REFERENCES}

1. พ. B. Stilwell, W. K. Hall, and S. Tawhai, "Ground Movement in New zealand Geothermal Fields," in Proceedings of the 2nd U. N. Symposium on the Development and use of Geothermal Resources, San Francisco, CA, May 20-29, 1975, pp. 1427-1434 (1976).

2. B. E. Lofgren, "Monitoring Ground Movement in Geothermal Areas," in Hydraulic Engineering and the Environment, Proceedings of the Hydraulic Division Specialty Conference, ASCE, Bozeman, Montana, August 15-17, 1973, pp. 437-447.

3. B. E. Lofgren, "Measuring Ground Movement in Geothermal Areas of Imperial Valley, California," presented at Jet Propulsion Laboratory, NSF Geothermal Energy Conference, Pasadena, California, September, 1974, p. 14 .

4. P. M. Otway, "Report on Results on Precise and Tilt-Leveling: Broadlands Reinjection Project, 1968-1976," presented at the International Conference Geothermal Reservoir, Wairakei, New Zealand, August 29-September 3, 1976.

5. J. P. Green, "An approach to Analyzing Multiple Causes of Subsidence," Soc. Pet. Eng. AIME 4079, 5 (1972). 


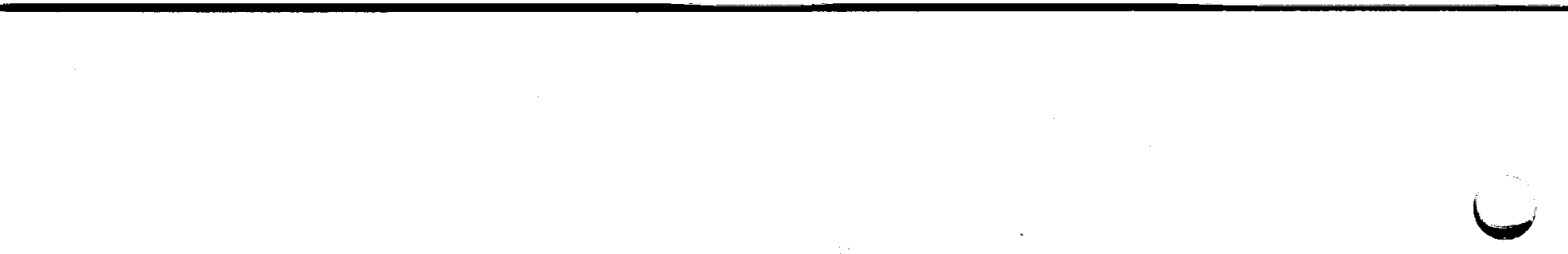




\section{RESEARCH CATEGORY 3}

\section{Direct Monitoring Instrumentation*}

\section{Background}

Present methods for measuring compaction at depth in a well are limited. Improved measuring capabilities are needed to withstand the depths and hostile environments anticipated for geothermal reservoirs.

Currently, direct monitoring instrumentation for measuring vertical movement at depth includes anchored-cable extensometers, free-pipe extensometers, casing-collar logging, and radioactive bullet logging. The anchored-cable and free-pipe extensometers are shown in Figure B-11. They require multiple-depth emplacements to measure compaction at specific depth intervals. The time-rate measurement is obtained by use of continuous or periodic recordings. Anchored-cable extensometers currently are operating to depths of $2300 \mathrm{ft}$ and free-pipe types to depths of $3300 \mathrm{ft}$. Problems resulting from using these instruments in geothermal environments include increasing frictional arag, corrosion, and temperature considerations.

* Announced in the Commerce Business Daily, September 13, 1976, as Category 3. 


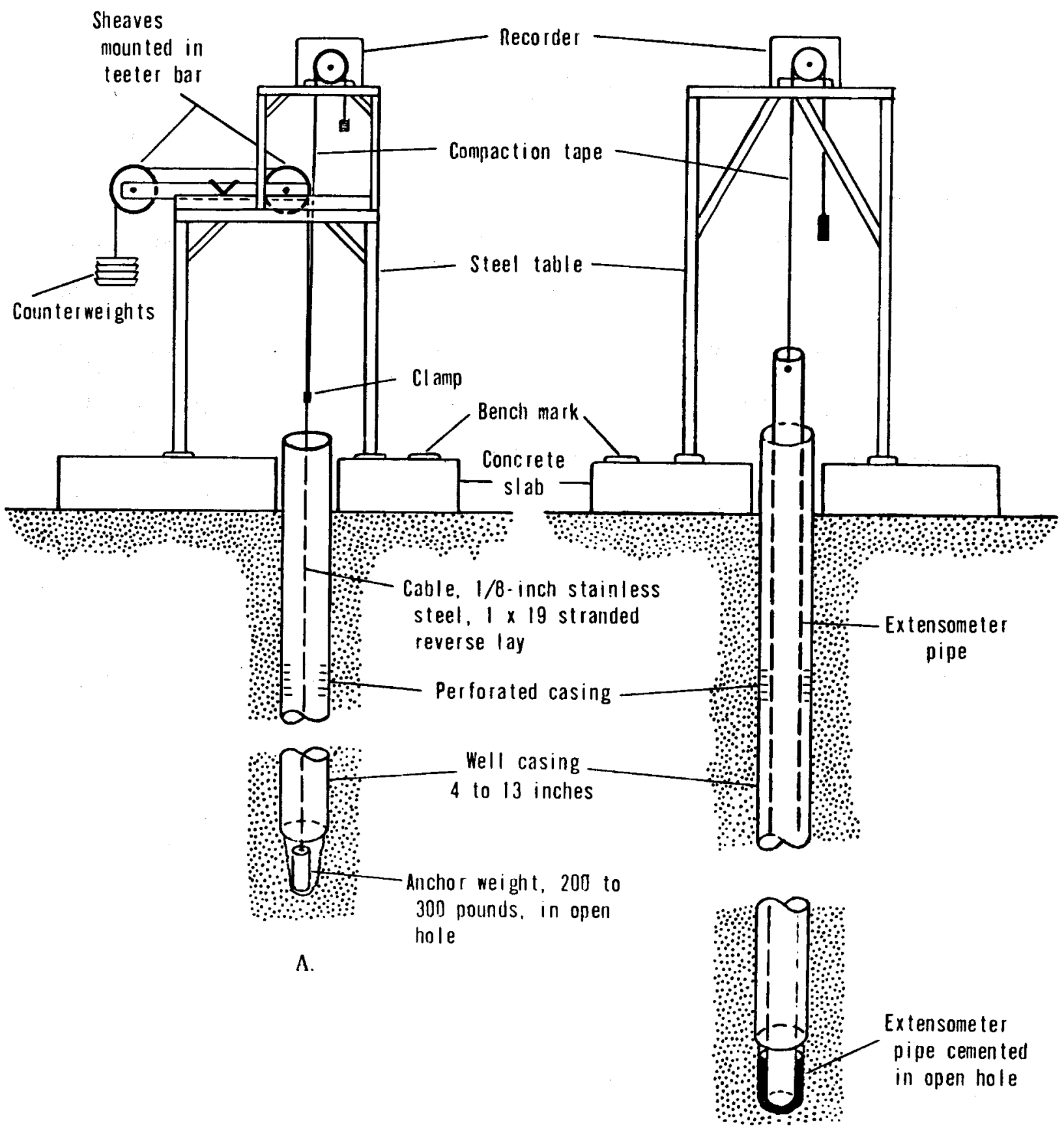

B.

XBL 774-8432

Figure B-11. Recording Extensometer Installation. A. Cable Assembly; B. Pipe Assembly. 
The casing-collar logging techniques, developed at the wilmington Oil Field in Long. Beach, California, have been used to depths of approximately $6000 \mathrm{ft}^{2}$ They provide a record of change in length of individual casing joints compared to the joint lengths placed in the well, or to a prior collar logging. The temperature ceiling of the equipment has not been fully evaluated, but is probably about $180^{\circ} \mathrm{C}\left(350^{\circ} \mathrm{F}\right)$, the melting point of solder. Recent developments in casing-collar logging at wilmington provided an accuracy of $0.03 \mathrm{ft} 88.58$ of the time for joint lengths of 40-44 ft measured three times. The maximum degree of instrument error is estimated to be $0.10 \mathrm{ft}$ for each joint length.

The conditions in cased boreholes in incompetent sediments differ from those in competent rocks. When a borehole is drilled in incompetent sediments, the formation moves under the geostatic load to grip the casing firmly. Field evidence obtained at wilmington oil Field strongly supports the theory that in the compacting zones the casing shortens in exact accord with the contiguous sediments, as a result of the skin friction. In competent rocks, on the other hand, the walls of a borehole may stand open permanently. When cased, little or no skin friction may be developed on the casing wall. Under such conditions the annular space between the rocks and the casing wall would have to be filled with cement in order to use the casing-collar technique.

At Wilmington, California, in Venezuela, at Niigata, Japan, and at the Groningen Gas Field in the Netherlands, radioactive bullets shot into the formation at known depths were resurveyed by a radioactivity detector system for measuring possible compaction. The detector system 
used at wilmington was reported by Allen $^{3}$ to be sensitive to heat, and for testing purposes was kept in a container with dry ice. Thus, temperature seems to be a principal limiting factor in depths obtainable with present techniques. The accuracy of the radioactive-bullet logging equipment used at wilmington is reported by Allen to be at best approximately $0.1 \mathrm{ft}$ per distance between bullets (which at wilmington was 20 feet) when logging at $25 \mathrm{ft}$ per min.

The accuracy of measurement is reported ${ }^{4}$ to have been improved at Groningen. To avoid spurious peaks, the detector assembly was run at a very slow rate--about $0.3 \mathrm{~m} / \mathrm{min}$. The logging-time requirements are large--about $24 \mathrm{~h}$ to $\log 460 \mathrm{~m}$ of formation, but an accuracy with a mean error of $1 \mathrm{~cm} / 100 \mathrm{~m}$ is claimed.

Direct monitoring instrumentation needs to be developed so that information about stressed regions of the geologic structure can be available to reservoir operators. The operators can use this information to estimate the rate of subsidence that might be expected on the surface. The subsidence results from displacements and differential compaction at depth. Such movements at depth would be due to the removal and/or injection of fluids in the reservoir.

Warning of possible subsidence could be supplied by instrumentation recording differential compaction at depth within the reservoir. Thus, direct information on the magnitude of compaction in the reservoir may allow field operators to appraise possible changing conditions at land surface at an early date. Correlative information at land surface 
would not be available until the subsidence had reached the surface and only when a precise leveling net had been rerun.

The possibility of measuring lateral deformation should be consldered in this research category. However, the emphasis should be on vertical movement, with lateral measurement a secondary level of research interest at this time. There are two reasons for this. Lateral movement at depth has not been measured to date, and methods are not yet available or sufficiently accurate. Furthermore, where lateral movement has been measured at land surface in subsiding areas, it has been much smaller than the maximum vertical movement.

It is necessary to improve current instrumentation or to develop new instrumentation. However, advanced electronics technology may be used to improve the accuracy, ease of use, and cost of measurement. One example is the use of a standing-wave pulse to determine the length of a wire in a well to indicate subsidence at various depths as a function of time.

Techniques must be explored for extending the depth capabilities of instruments. These instruments will have to withstand very hostile conditions at substantial depths. Problems to be overcome include:

- Major Temperature Excursions and Cycles - $100^{\circ}-375^{\circ} \mathrm{C}\left(212^{\circ}-700^{\circ} \mathrm{F}\right)$

- High to Very High Pressures - 200-900 kg/cm ${ }^{2}(3000-13000$ psi)

- Corrosive Solutions

- Dissolved Solids Range (5000 - $100000 \mathrm{mg} / 1 \mathrm{tter})$

- Multiple Fluid Phases

- Nonlinearity of Well Bores 
- Inconsistent Use of Well Casings

- Changing Casing Diameters

- Instrumentation Cable Twist, Friction, and Bounce.

\section{Statement of the Problem}

Current instruments either cannot operate within the 5000 to 20,000 ft range required, or they cannot withstand the in situ geothermal conditions. Without such measurement capabilities, predictive subsidence theory and models cannot be confirmed, and precursor measurements cannot be obtained.

\section{Discussion of a Solution}

Improvements in present instruments or new instruments are required for direct measurement of subsidence and expansion phenomena at great depths. To conduct this research, possible instrument concepts should be identified, and prototypes should be built and tested.

Research Objective

Develop the capability to measure the vertical distance between two points in a geologic formation at depth. The accuracy will be at least $0.05 \mathrm{ft}$ per $100 \mathrm{ft}$ of interval distance (i.e., 1:2000 per $100 \mathrm{ft}$ ). Measurements must be made under hostile conditions of temperature, pressure, and salinity.

\section{Research Projects}

Figure B-12 shows the arrangement of tasks in the research project. There will be two or more separate projects in this category: Project 1 
C

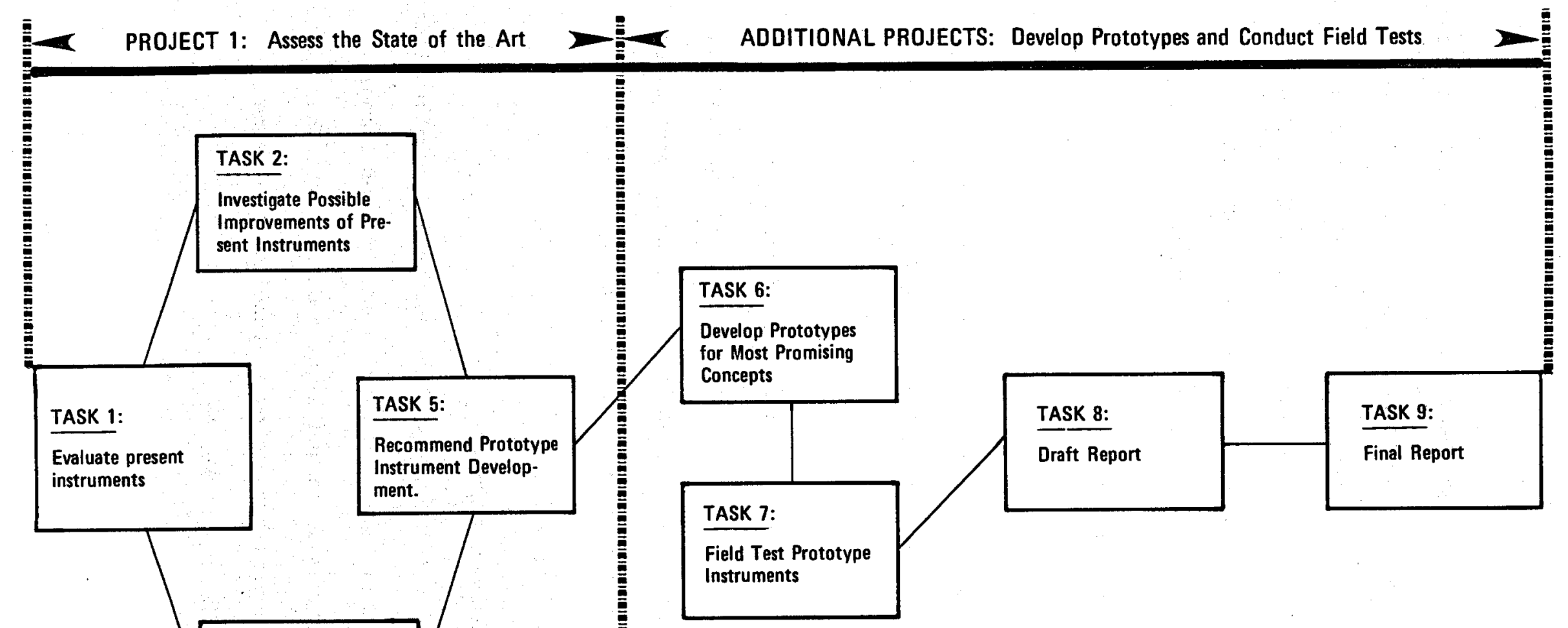

\section{TASK 4:}

Identify new measure.

ment concepts.

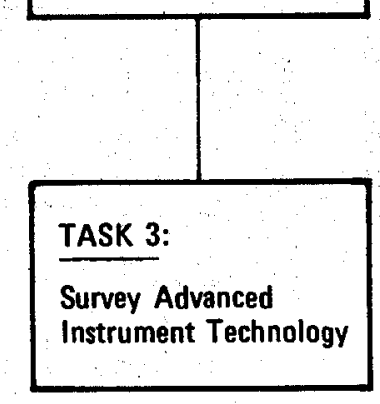

Figure B-12. General Schedule: Development of Differential Compaction or Expansion Monitoring Instrumentation. 
consists of Tasks 1 through 5 - Assess the state of the art and recommend concepts for prototype development. Additional projects will consist of Tasks 6 through 9 - Develop prototypes and conduct field testing. It should be noted the tasks outlined are meant to be representative of actions necessary to reach the objective. The process proposed and used is the responsibility of the research contractor.

PROJECT 1 - ASSESS THE STATE OF THE ART

Task 1 Evaluate Present Instruments.

Review present instruments and methods, including casing-collar logging, extensometers, radioactive bullet logging, and acoustic televiewers.

Task 2 Investigate Possible Improvements of Present Instruments. Improved instruments will be compared with new measurement concepts, defined in Task 4. Such comparisons will assist in selecting prototypes for testing and evaluation. One to three promising alternatives may be selected for upgrading.

Task 3 Survey Advanced Instrument Technology. Instrument suppliers and researchers will be surveyed for information on advanced technology that might apply to this category. For example, results might recommend using the technique mentioned earlier. That is, measuring the length of a wire by sending a standing wave pulse through the wire and measuring the feedback. 
Task 4 Identify New Measurement Concepts.

New concepts will be described in detail so comparisons can be made based on capital and operating cost, degree of accuracy, etc.

Task 5 Recommend Prototype Instrument Development.

Develop a method of comparing improved present instruments with the new measurement concepts.

Criteria for comparing alternative concepts should include:

- Potential for Research Success

- Reliability

- Flexibility of Use (Observation vs Production Well Usage)

- Cost of Instrumentation

- Cost of Measurement Operations

- Degree of Suitability for Monitoring (Continuous or Periodic)

- Degree of Accuracy

- Repeatability of Measurement Results

- Utility in Groundwater and Hydrocarbon Fields

- Ease in Automating Data Retrieval

ADDITIONAL PROJECTS - DEVELOP PROTOTYPES AND CONDUCT FIELD TESTING

Task 6 Develop Prototypes for Most Promising Concepts.

Prototype instruments will be built for $1 \mathrm{ab}$ and field testing. The number of prototypes to be built would be determined in this task. Laboratory testing and calibration will also be performed in this task. 
If appropriate, this task may be conducted on a subcontractual basis or form the basis for separate contracted services.)

Task 7 Field Test Prototype Instruments.

The prototypes will be field tested. This includes developing test procedures to assure accurate results and a comparison of the results.

Task 8 Draft Report.

The results of the research project to this point should be critically reviewed. A draft report will be prepared and may be presented at a workshop seminar or to a committee of selected professionals. Recommendations for conducting the review are required in the proposal.

\section{Task 9 Final Report.}

The final report will include descriptions of:

- Selection Process

- Tabulation of Testing Data

- Results and Conclusions

- Instrument Specifications and Design

- Recommendations for Production and Application

\section{Priority}

The development of instruments to accurately measure subsidence has a high priority. 


\section{Interfaces}

The results of this research will be used in other research categories. For example, results will:

- Provide to additional projects in this category the basis to build and test prototype instruments.

- Provide data to support physical theory, defined in Research Category 5. The results will also help assess indirect techniques for estimating deformation in Research Category 6.

- Provide monitoring instruments needed to develop monitoring methods in Research Category 2.

- Provide correlation of monitoring, modeling, and approved operational procedures in Research Categories 8 and 9.

\section{Summary of Products and Milestones}

A report will be distributed upon completion of Project 1 . This report will include recommendations of the prototypes for future development, field testing, and validation. Project 2 requires an interim report described in Task 8 and a workshop or seminar. The product from Project 2 will be one or more instruments ready for use in direct monitoring programs. 
1. J. F. Poland, "Land Subsidence Stopped by Artesian-Head Recovery, Santa Clara Valley, California," in Proceedings of Second International Symposium on Land Subsidence, Anaheim, CA, AIHS Pub. No. 121,1977 (in press).

2. D. R. Allen (private communication), Feb. 1977.

3. D. R. Allen (private communication), Nov. 1976.

4. J. B. Schoonbeck, "Land Subsidence as a Result of Gas Extraction in Groningen, The Nether lands," in Proceedings of Second International Symposium on Land Subsidence, Anaheim, CA, AIHS Pub. No. 121,1977 (in press). 


\section{RESEARCH CATEGORY 4}

\section{Environmental and Economic Effects Caused by Varying Degrees of Land Subsidence*}

\section{Background}

Planners must be aware of the potential environmental and economic impact caused by varying degrees of land deformation. This land deformation may be caused by geothermal fluid production and injection. Impacts may include damage from ground movement or costs incurred in preventing or repairing damage. Impacts may also include environmental effects, which may not be easily quantified in monetary terms, but are of concern nonetheless.

Two major factors influence the potential for subsidence and, should it occur, the severity of subsidence. The first is equipment design and operation as they affect the distribution and quantity of withdrawn and injected fluid. The geological structure and geohydrologic characteristics represent the other major factor.

\section{Statement of the Problem}

Information on potential environmental and economic effects is needed in the planning process when there is a possibility of subsidence. Such effects will vary greatly depending on many factors. Land use is one of the most influential factors. In geothermal areas with high population densities and/or intense agricultural or industrial usage,

*Announced in the Commerce Business Daily September 13, 1976 as Category 9. 
little subsidence would be tolerated. In contrast, many potential geothermal areas are located where subsidence could be acceptable. The evaluation of such effects prior to the authorization of a geothermal facility would assist the approval process and the operational phase.

\section{Discussion of a Solution}

Currently there is little published environmental or economic impact data on subsidence caused by the withdrawal of fluids (hydrocarbons, groundwater, or geothermal fluids).

Two methods will be used to obtain such data. The first is to compile data from areas already subjected to subsidence. The second is to evaluate the environmental and economic impact of subsidence in prospective geothermal areas based on geology and land use.

\section{$\underline{\text { Research Objectives }}$}

- Compile data on the environmental and economic effects of subsidence.

- Investigate the environmental and economic effects of varying degrees of subsidence.

- Investigate means to mitigate the effects through prevention or repair.

\section{Research Projects}

Figure B-13 shows the recommended research projects to meet the research objectives. 

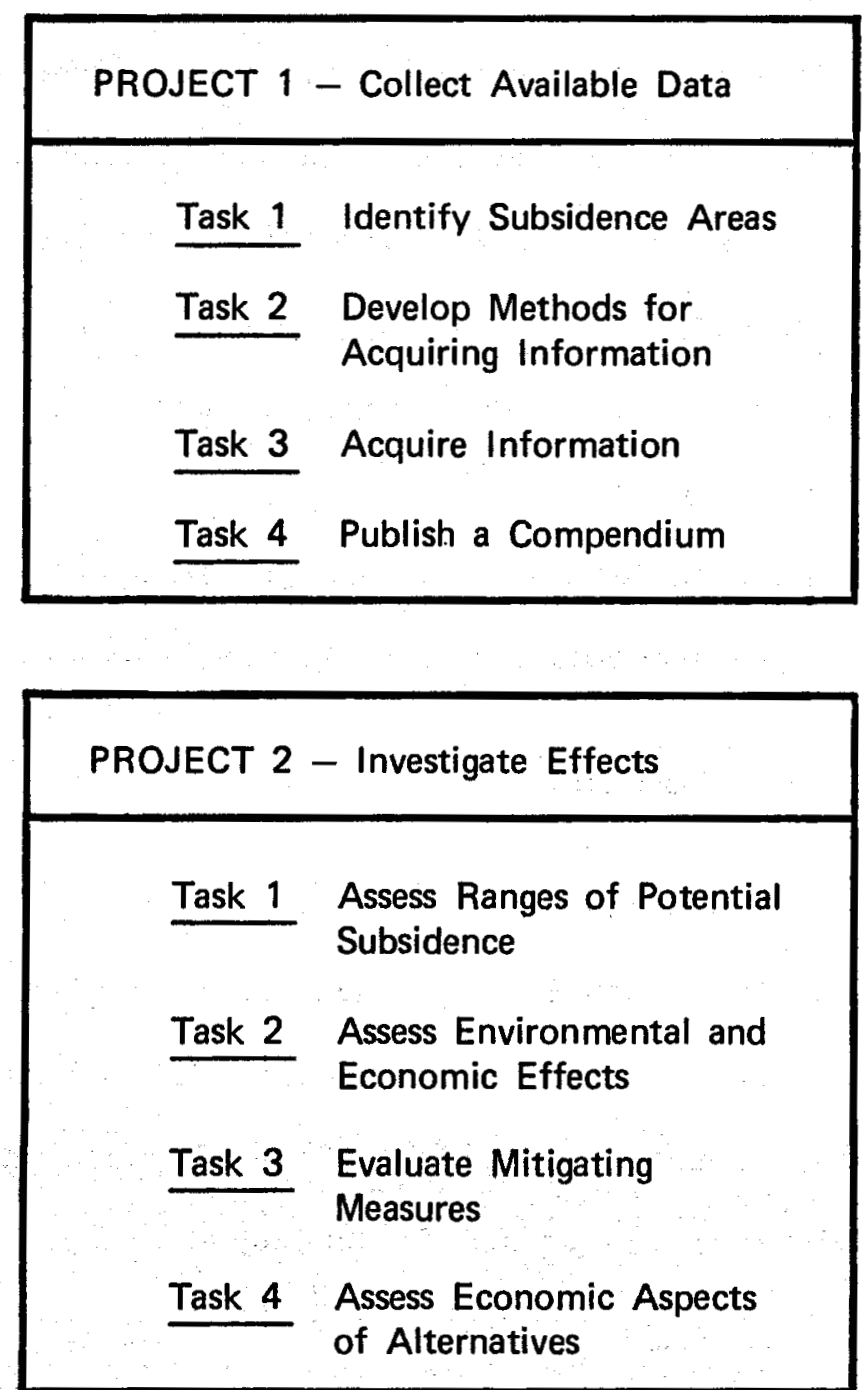

XBL 774-8434

Fig. B-13. Environmental and Economic Assessment. 
Project 1 identifies, acquires, and disseminates data on subsidence effects in selected areas. A questionnaire may be designed for use during interviews, and procedures may be developed for continuous acquisition of data.

Project 2 assesses the range of environmental and economic effects based on a variety of geological and land use settings. The various settings will be selected by ERDA's Division of Geothermal Energy. The number of settings may range from 5 to $20^{1}$ The Lawrence Berkeley Laboratory will provide a range of subsidence, both degree and form, to be considered.

The following task descriptions are provided as recommendations. Alternative means to accomplish the tasks may be considered.

PROJECT 1 - COLLECT AVAILABLE DATA

Task 1 Identify Subsidence Areas.

Land surface and subsurface movement has occurred in certain areas around the world due to the extraction of fluids (groundwater, hydrocarbons, and geothermal fluids). Several locations are listed below as possible starting points for the study. 


\section{Sample Locations ${ }^{2}$}

- Australla - Morwell

- England - London area

- Italy - Venice, Po River Valley, and the Larderello and Monte Amiata Fields

- Japan - Tokyo, Osaka, Nilgata Plain, Nagoya City, Haranomachi, Saga Plain, and Aomori Plain

- Mexico - Mexico City and Cerro Prieto

- Nether lands - Groningen Field

- New Zealand - Wairakei, Kawerau, and Broadlands

- Taiwan - Taipei Basin

- United States - Texas and Louisiana Gulf Coast, Arizona, and California (San Joaquin and Santa Clara Valleys, and wilmington oil Field).

The list does not mean there must be an international study. Rather, it indicates some alternative locations. In contrast, the list of locations in the United states is not sufficient.

Task 2 Develop Methods for Acquiring Information.

The availability of published data should be considered. Questionnaires and/or interviews may be required.

\section{Task 3 Acquire Information.}

The collection of data is a key activity that will affect the usefulness of this project.

Task 4 Publish a Compendium. 
PROJECT 2 INVESTIGATE EFFECTS

Task 1 Assess Ranges of Potential Subsidence.

The settings may include:

- Basin and range structures (e.g., Nevada)

- Rift valley structures (e.g., Imperial Valley and Rio Grande graben)

- Volcanic calderas (e.g., Valles Caldera)

- Highly deformed and metamorphosed regions (e.g., The Geysers)

- Sedimentary basins containing geopressured systems (e.g., Northern Gulf of Mexico Basin)

These settings would then be evaluated according to land use, such as agricultural, suburban, industrial, and urban.

Task 2 Assess Environmental and Economic Effects.

Emphasis will be placed on major impacts, focusing on those that may be costly and identifying mitigating measures.

Task 3 Evaluate Mitigating Measures.

Measures to mitigate adverse effects will be studied and ways to implement these measures will be investigated.

Task 4 Assess Economic Aspects of Alternatives.

The economic effects should be quantified as practical, based on specific units. For example, the units might be acre-feet of water per year of canal carrying capacity lost. The determination of the cost of an acre-foot of water in a given region should also be given. 


\section{Priority}

With respect to other research categories, this category has been evaluated as high priority. Thus research in this category will be started early in the program.

\section{Interfaces}

This category does not strongly influence the other categories. Results from the two projects in this category will be able to stand alone as useful data. However, the data will indirectly affect operational policies to be formulated in Research Category 9.

\section{Products and Milestones}

A report will be published at the end of Project 1 . The milestones in Project 1 consist of accomplishing each of the tasks. A report will also be prepared at the end of Project 2 and the three tasks are the milestones.

\section{REFERENCES}

1. Analysis of Geothermal Energy Development Scenarios, The Mitre Corporation, ERDA-DGE, Contract No. E(49-18)-2268, MTR-7220, November 1976.

2. Worldwide questionnaires on subsidence, developed by A.I. Johnson of the U.S. Geological Survey, National Center, Reston, VA, may provide further international assessment data. 


\section{RESEARCH CATEGORY 5}

\section{Physical Processes of Subsidence*}

\section{Background}

Availability of theory adequately describing the physical processes of subsidence will be an important adjunct to the geothermal development program. Computer codes and other analytical tools are based on theory. Individuals involved should be able to use these tools to analyze development and operations to minimize subsidence as well as to maximize resource recovery. A great deal of literature exists on the theory of physical processes. Such literature is based on soil mechanics and hydrogeology of porous media. The applicability of such theory to a deep geothermal system, which may have undergone hydrothermal alteration and may be subject to tectonic stress, may not be appropriate.

\section{Statement of the Problem}

A major shift in theoretical perspective may be needed to explore the physical processes of subsidence. The traditional interest of hydrologists and petroleum engineers has been volume and rate of fluid flow. Fluid rates of movement are much greater than skeletal rates (rock matrix deformation). Thus, the skeletal rates have been ignored with negligible error for the purpose of estimating the transient distribution of fluid pressure and fluid flow. However, to predict

\footnotetext{
\# Announced in the Commerce Business Daily, September 13, 1976, as Category 1.
} 
cumulative vertical and lateral movement of the land surface, it is the neglected skeletal displacement field that needs an adequate theory. Several geothermal-related subsidence theories have been postulated and a number of them have been adapted to computer codes. ${ }^{1}$ It is important to confirm the theories by field tests.

Analysts should investigate a number of fundamental physical processes that cause subsidence. They should understand and explain these processes, such as:

- The relationship of the lateral displacement field to the vertical displacement field.

- The upward migration of a stress field and resulting skeletal movement (lateral and vertical) from the reservoir through the overburden to the land surface.

- The difference between the compressional behavior of a reservoir (directly stressed environment) and that of overburden material (indirectly stressed environments).

- The effect of fluid velocity on lateral skeletal displacement in a reservoir.

- The relationship between the mechanical properties of a system at depth and its thermal and pressure properties.

- The differences in natural response due to the compaction of unconsolidated and consolidated material. Examples of subtopics are: the difference between bulk fracture-compressibility and intergranular pore-compressibility; effects of lithification on compressional properties. 
- The importance of fractures, their density, geometry, and orientation to subsidence potential.

- The influence of grain orientation, shape, size, and mineral content (for example, mica content of sand) on compaction properties of material.

- The variations in skeletal response due to (1) a gradual decrease in pore pressure (2) a sudden step decrease in pore pressure, and (3) a gradual increase in total load.

- The effect of loading (e.g., cyclic loading) on skeletal behavior.

- The relationships of nonrecoverable skeletal behavior to recoverable behavior.

- The differences in the transient behavior of skeletal material from its ultimate response to the same stress.

- The effect of pumping on the thermal (or pressure or mechanical) properties of a reservoir. Determine whether the in situ elevated temperature (or pressure) boundaries of a reservoir move vertically or laterally due to systematic induced changes in fluid pressure.

\section{Discussion of a Solution}

Investigation of the physical processes of subsidence will require a comprehensive review and understanding of existing theory. Research projects will be needed to provide information to explain the fundamental physical processes responsible for subsidence. 
$\underline{\text { Research Objectives }}$

The objective of research in this Category is to understand the physical processes of material behavior related to geothermal systems and their potential to produce subsidence.

$\underline{\text { Research Project Tasks }}$

The suggested activities involved in investigating the issues are indicated below (Tasks 1-3).

The major responsibilities of a researcher proposing to investigate the physical processes of subsidence are indicated below.

Select an objective (or set of objectives) pertaining to the physical processes of land subsidence that is unanswered or incompletely answered, and is of importance to geothermal reservoir planners and developers. Choose a method of attaining the selected objective(s). The selection of a good set of objectives presupposes prior in-depth (1) review of published subsidence theory, (2) review of published and unpublished data, (3) interviews with field and laboratory investigators, and (4) determination of gaps in theory. The choice of a method of achieving the selected objective(s) presupposes capability of (1) research staff and (2) facilities of research institution not only to solve the proposed problem but to corroborate the solution. Corroboration can be done either with existing data (published or unpublished) or with data (field or laboratory) collected as part of the proposed project. 
Task 1 Perform Research and Formulate Theory.

Research will be performed pertaining to the objectives selected.

The research should be designed to provide information for practical

application to models of the physical processes of subsidence.

\section{Task 2 Present Results of Research.}

Research results should be presented at a scientific seminar

or other open forum. The objective will be to get an interchange

of research information between the research projects and the scientific community.

\section{Task 3 Document Results.}

The emphasis will be on presenting information in a way that practical applications will be facilitated.

\section{Priorities and Interfaces}

The research in this category will be started in the latter portion of fiscal year 1977 .

Reviews of case histories in Category 1 might indicate the need to focus research activities. Categories 3 and 6 deal with the development of instruments, which should provide the basis for proving existing physical process theory or formulating new theory related to geothermal systems.

\section{Summary of Products and Milestones}

The scope of work in this research category is subject to the receipt of proposals. However, a major milestone will be a publication of a final report(s), including source information. 


\section{REFERENCE}

1. Systems Control, Inc., "The Analysis of Subsidence Associated with Geothermal Development," Vol. 2, Chap. 7, 1976 (NSF Grant AER 75-17298). 


\section{RESEARCH CATEGORY 6}

\section{Indirect Techniques to Estimate Subsidence at Depth*}

Background

Indirect techniques for measuring subsidence include methods of correlation between compaction, differential displacement, or surface motion, and the bulk properties of the reservoir rock and/or fluid. Direct methods of measuring subsidence are limited because they are typically made in boreholes, or involve measuring surface motions. But surface motions may occur long after the subsurface displacements have occurred. Using boreholes also means that the monitoring of subsidence is limited to regions sampled by wells or special-purpose boreholes. Methods are needed that are based on the detection of changes in the bulk properties of the reservoir rocks and/or fluids during production. Using correlations between compaction and subsidence, changes in the bulk properties of the reservoir would allow a much greater volume to be sampled. This would be advantageous if surfacemeasurement techniques could be developed. For example, if gravity or resistivity measurements (which can be made at the surface) could be correlated with subsidence, then regions outside of the well area could be monitored. Since indirect methods could monitor a larger area than direct methods, the cost may be much less than for direct methods. Indirect methods could also be used as survey

* Announced in the Commerce Business Daily, September 13, 1976 as Category 9. 
tools over large areas. Thus the accuracies would not need to be as high as required when using the direct methods, which must be integrated to provide estimates of surface motion. When indirect methods indicate possible subsidence, direct methods could be used to monitor the trouble area. The indirect methods could thus provide an early warning that could be followed up with direct methods.

\section{Statement of the Problem}

During geothermal production the bulk properties (both rock and fluid) change due to the changes in pressure and temperature. The changes in bulk properties depend on:

- The amount and rate at which the fluids and heat are withdrawn from the reservoir.

- The fluid and heat recharge.

- The in situ stress distribution. To use indirect methods, which depend on small changes in the bulk properties, two problems must be solved. They are:

- Measuring those parameters that can be related to subsidence.

- Constructing theories relating the bulk parameters and subsidencerelated properties, such as differential displacement, in the reservoir formation.

Improved field-measurement equipment and new measurement techniques are required for accurate determination of changes in the reservoir bulk properties. New theories are needed to relate parameter measurements to subsidence. 


\section{Discussion of a Solution}

There are several bulk properties of the reservoir fluid and rock that might be useful in estimating subsidence by indirect methods. They are:

\section{Temperature}

2. Pressure

3. Fluid flow rate

4. Fracture characteristics

5. Fluid composition

6. Permeability

7. Porosity directly to subsidence-related compaction. But, for example, a well test using instruments that measure pressure, temperature, and flow rate might provide accurate estimates of permeability and porosity. These could then be related to subsidence. Fractures, interbedded inhomogeneities, varying lithology, mineralogy, and fluid composition complicate establishing a theory relating the bulk parameters and subsidence. However, well testing is a well-developed technology. Thus it may be possible to obtain the accuracies necessary to establish such a theory.

Other possibilities include the measurement and correlation of fracture properties with formation compaction; the change in the bulk resistivity with a change in porosity, fluid composition, and temperature; 
the differential changes with seismic velocity in the reservoir formation as a function of pressure, temperature, porosity, etc.

In these examples it is assumed that instruments and techniques can be adapted that have sufficient accuracy and repeatability to achieve correlation between formation bulk properties and the small, but important, changes in the formation.

A major requirement of the research will be the derivation of the correlations between bulk properties and the subsidence-related formation movement.

\section{Research Objectives}

There are three areas in which research must proceed. The first requires examining existing theories and measurement capabilities to see what can be accomplished with improved measurement techniques and instruments. The second and third areas require developing new theories between bulk properties and subsidence, developing new or improved instruments and measurement techniques.

\section{Research Project Tasks}

This research category may be divided into two projects, each having several tasks. Project 1 will necessarily be completed before Project 2 begins. The actual approach is the responsibility of the proposing contractor. 
PROJECT 1 - ASSESS INDIRECT TECHNIQUES

Task 1 Review Technique. Review techniques and instruments for measuring bulk parameters from boreholes and from the surface.

Task 2 Review Theories. Review theories relating bulk parameters and subsidence-related formation changes (e.g., Archie's law, effective stress, etc.).

Task 3 Required Accuracy. Determine accuracies needed for correlation of bulk property changes and subsidence-related changes using theories. Task 4 Recommendations. Recommend instruments, techniques, and theories for making the correlations.

PROJECT 2 - DEVELOP PROTOTYPES AND TESTING

Task 1 Build Prototypes. Build prototype instruments and establish techniques for the measurement of the bulk properties.

Task 2 Develop New Theories. Develop new theories (which might depend on new instruments) for correlating the indirect methods of determining subsidence.

Task 3 Specify Field-Testing Programs.

Task 4 Perform Field Tests.

Task 5 Evaluate Field Tests.

\section{Priorities}

Indirect means for detecting subsidence has a lower priority than the development of direct measurement techniques (Category 3). However, such indirect techniques would prove useful in the operational 
phase of a project. Due to the lead times needed to develop instruments, this research will be undertaken early.

Interfaces

Project 1 may provide information to assist in planning Research Categories 5 (Physical processes) and 7 (Laboratory Testing). The field testing of direct (Category 3) and indirect (Category 6) prototype instruments could be jointly done to produce comparable results and reduce costs.

Summary of Products and Milestones

A major milestone will be a report on instruments and techniques for indirect measurement of subsidence. Another milestone will be a final report including a method for using indirect measurements to estimate actual displacements and differential compaction. 


\section{RESEARCH CATEGORY 7}

\section{Laboratory Testing*}

\section{Background}

The quantitative compaction characteristics of sediments from great depths are largely unknown. Specific physical data for conditions simulating geothermal basins are lacking.

If volume changes caused by sediment compaction or expansion are negligible, then potential subsidence of geothermal basins must be caused by other mechanisms. If volume changes are significant, then they will provide a basis for estimating the rate of subsidence due to compaction.

Currently the Energy Research and Development Administration is sponsoring laboratory tests of samples under conditions that simulate the temperature, pressure, and chemical environments of geothermal areas. The value of such tests hinges on the ability to realistically simulate and measure the responses of deeply buried geologic materials. Unfortunately, many of the factors causing subsidence of material in geologic environments are difficult to reproduce. For instance, subsidence may be due to movement along fractures of widely differing size, orientation, and spacing. The problem of simulating fracturerelated subsidence has yet to be addressed. Thus the challenge of laboratory testing may not be the reproduction of just the downhole environment, but also the nonhomogenous nature of fractured materials. * Announced in the Commerce Business Daily, September 13, 1976 as Category 5. 
Statement of the Problem

Laboratory tests in simulated geothermal environments are being conducted to determine bulk rock properties. However, movement along fractures in rock may be more important to understanding subsidence.

Discussion of a Solution

Current laboratory testing capabilities may provide a basis to determine:

(1) The rate and magnitude of material volume changes that accompany changes in temperature and pressure. Data of this type will be useful to evaluate:

(a) The zones surrounding and overlying a geothermal reservoir that may contribute to subsidence.

(b) The magnitude of surface subsidence, if any, that might accompany development of a geothermal reservoir.

(c) Special conditions or procedures for extraction and replacement of geothermal fluids that might be used to minimize detrimental effects.

(2) Mineralogical transformation, if any, accompanying changes in pressure, temperature, and chemical properties.

Thus the laboratory testing program now in progress is being monitored, keeping in mind the need to simulate the stress responses of fractured material. 
Research Project

Pending the outcome of the current laboratory testing program, a similar program focusing on the stress responses of fractured material may be recommended.

Should this research be required, it may be done using laboratory techniques or, due to complexity, it may require mathematical modeling.

Priority

Because of the present testing program, this Research Category has been delayed.

Summary of Products and Milestones

No products are identified at this time. A milestone to decide whether to undertake additional research in mid-FY 1978 is recommended. 



\section{RESEARCH CATEGORY 8}

\section{Subsidence Models*}

Background

In planning a geothermal reservoir, analytical tools should be available to estimate potential subsidence, so appropriate measures can be planned. Modeling techniques are available that could provide analytical tools. However, it is not known whether present models are capable of providing accurate predictive results. Therefore, research needs to be done to evaluate available subsidence models.

Mathematical models, using high-speed computers, exceed physical models as predictive tools for the behavior of complex systems. Physical models provide a means of validating mathematical models as applied to simple systems. For this reason, the focus will be on mathematical models.

Statement of the Problem

The problem is whether or not available mathematical models are adequate to accurately estimate subsidence. Once available subsidence models have been evaluated, additional research may be necessary to develop advanced models to meet the needs of the geothermal program.

As applied to geothermal systems analysis, subsidence modeling can be divided into two parts:

* Announced In Commerce Business Daily, september 13, 1976 as Category 8. 
(1) simulation of reservoir deformation. The reservoir deforms due to internally generated stresses resulting from the reaction of pore fluid pressures.

(2) Simulation of deformation of the overburden. The overburden deforms due to displacements at its interface with the deforming reservoir.

\section{Reservoir Deformation}

Two approaches have been employed for modeling reservoir deformation. The first is the one-dimensional consolidation incorporating the theory of Terzaghi, which considers only vertical strains. In various forms this theory has been successfully employed by soil engineers for ground settlement problems. 1 Gambolati and Freeze ${ }^{2}$ and Helm ${ }^{3}$ followed this approach to model subsidence related to shallow groundwater reservoirs.

The advantages of the one-dimensional approach are as follows:

(a) The use of a single governing equation (the drainage equation).

(b) Accounting for recoverable as well as nonrecoverable compaction.

(c) Simultaneous handling of pore-fluid pressure change and deformation.

(d) Reasonable validity of the assumption of negligible lateral strains when deformation mainly occurs in clay or shale caprocks or interbeds draining vertically into adjacent sands.

(e) Availability of past experience in applying the theory to engineering field problems. 
There is strong evidence that in certain areas subsidence may be accompanied by significant horizontal displacements. 4 The one-dimensional consolidation theory is inadequate to model horizontal displacements. For simulating deformation in a general sense, three-dimensional stress-strain theories have been developed. Essentially, these models solve two coupled governing equations. The first is a diffusion equation describing fluid flow, and the second is a force balance equation relating stress and strain. The flow equation assumes that the pore fluid pressure decreases in a volume element in proportion to the volume of fluid drained. The change in pore fluid pressure induces changes in skeletal stresses, which in turn cause a change in the bulk volume of the element. The fluid-flow equation and the stress-strain equation are coupled suitably in order to assume compatibility of volume change.

An important component of these models is the nature of the constitutive laws employed. These laws are required for:

(a) Relating pore-pressure change to changes in skeletal stresses.

(b) Relating volume deformation to lateral and vertical strains.

(c) Relating stress and strain.

Various effective stress laws can be used for relating porepressure change and skeletal-stress change. The simplest assumes that change in pore pressure affects only the normal stress components. The concept of Poisson's ratio, developed in the theory of elasticity for small strains, has generally been extended to saturated soils. It is used extensively for relating volume strain to lateral and vertical strains. 
A number of constitutive laws have been developed to relate stress and strain. 5 These laws range in complexity from simple elastic models to visco-elastic and plastic models. These constitutive laws may be further modified by taking into account temperature effects.

The generalized approach is technically superior to the simple onedimensional deformation approach in that it is able to model the physical system in far greater detail. But the generalized approach also requires greater effort for obtaining meaningful results. Moreover, the generalized models also require a larger number of input parameters. Often, available field data may be grossly insufficient to provide these input parameters. Thus the justification for performing sophisticated simulation in some cases is doubtful.

The constitutive laws currently used are based on concepts well suited for systems subjected to external loads acting on the system boundary. It is not clear how well these laws represent lateral and vertical displacements in unconsolidated or poorly consolidated sediments in which grains may be dragged in the direction of fluid movement. At the same time it is not entirely clear whether granular movement is significant in deep-seated reservoirs. At present, very little field data are available in regard to the variation of horizontal and vertical displacements as a function of depth. Without such field data a relevant theory is hard to formulate. Hopefully, during the next year or two, research work under Category 1 will provide useful preliminary information. 
There is strong evidence that in certain areas subsidence may be accompanied by significant horizontal displacements. 4 The one-dimensional consolidation theory is inadequate to model horizontal displacements.

For simulating deformation in a general sense, three-dimensional stress-strain theories have been developed. Essentially, these models solve two coupled governing equations. The first is a diffusion equation describing fluid flow, and the second is a force balance equation relating stress and strain. The flow equation assumes that the pore fluid pressure decreases in a volume element in proportion to the volume of fluid drained. The change in pore fluid pressure induces changes in skeletal stresses, which in turn cause a change in the bulk volume of the element. The fluid-flow equation and the stress-strain equation are coupled suitably in order to assume compatibility of volume change.

An important component of these models is the nature of the constitutive laws employed. These laws are required for:

(a) Relating pore-pressure change to changes in skeletal stresses.

(b) Relating volume deformation to lateral and vertical strains.

(c) Relating stress and strain.

Various effective stress laws can be used for relating porepressure change and skeletal-stress change. The simplest assumes that change in pore pressure affects only the normal stress components. The concept of Poisson's ratio, developed in the theory of elasticity for small strains, has generally been extended to saturated soils. It is used extensively for relating volume strain to lateral and vertical strains. 
A number of constitutive laws have been developed to relate stress and strain. 5 These laws range in complexity from simple elastic models to visco-elastic and plastic models. These constitutive laws may be further modified by taking into account temperature effects.

The generalized approach is technically superior to the simple onedimensional deformation approach in that it is able to model the physical system in far greater detail. But the generalized approach also requires greater effort for obtaining meaningful results. Moreover, the generalized models also require a larger number of input parameters. Often, available field data may be grossly insufficient to provide these input parameters. Thus the justification for performing sophisticated simulation in some cases is doubtful.

The constitutive laws currently used are based on concepts well suited for systems subjected to external loads acting on the system boundary. It is not clear how well these laws represent lateral and vertical displacements in unconsolidated or poorly consolidated sediments in which grains may be dragged in the direction of fluid movement. At the same time it is not entirely clear whether granular movement is significant in deep-seated reservoirs. At present, very little field data are available in regard to the variation of horizontal and vertical displacements as a function of depth. Without such field data a relevant theory is hard to formulate. Hopefully, during the next year or two, research work under Category 1 will provide useful preliminary information. 
There is strong evidence that in certain areas subsidence may be accompanied by significant horizontal displacements. 4 The one-dimensional consolidation theory is inadequate to model horizontal displacements.

For simulating deformation in a general sense, three-dimensional stress-strain theories have been developed. Essentially, these models solve two coupled governing equations. The first is a diffusion equation describing fluid flow, and the second is a force balance equation relating stress and strain. The flow equation assumes that the pore fluid pressure decreases in a volume element in proportion to the volume of fluid drained. The change in pore fluid pressure induces changes in skeletal stresses, which in turn cause a change in the bulk volume of the element. The fluid-flow equation and the stress-strain equation are coupled suitably in order to assume compatibility of volume change.

An important component of these models is the nature of the constitutive laws employed. These laws are required for:

(a) Relating pore-pressure change to changes in skeletal stresses.

(b) Relating volume deformation to lateral and vertical strains.

(c) Relating stress and strain.

Various effective stress laws can be used for relating porepressure change and skeletal-stress change. The simplest assumes that change in pore pressure affects only the normal stress components. The concept of Poisson's ratio, developed in the theory of elasticity for small strains, has generally been extended to saturated soils. It is used extensively for relating volume strain to lateral and vertical strains. 
A number of constitutive laws have been developed to relate stress and strain. 5 These laws range in complexity from simple elastic models to visco-elastic and plastic models. These constitutive laws may be further modified by taking into account temperature effects.

The generalized approach is technically superior to the simple onedimensional deformation approach in that it is able to model the physical system in far greater detail. But the generalized approach also requires greater effort for obtaining meaningful results. Moreover, the generalized models also require a larger number of input parameters. Often, available field data may be grossly insufficient to provide these input parameters. Thus the justification for performing sophisticated simulation in some cases is doubtful.

The constitutive laws currently used are based on concepts well suited for systems subjected to external loads acting on the system boundary. It is not clear how well these laws represent lateral and vertical displacements in unconsolidated or poorly consolidated sediments in which grains may be dragged in the direction of fluid movement. At the same time it is not entirely clear whether granular movement is significant in deep-seated reservoirs. At present, very little field data are available in regard to the variation of horizontal and vertical displacements as a function of depth. Without such field data a relevant theory is hard to formulate. Hopefully, during the next year or two, research work under Category 1 will provide useful preliminary information. 


\section{Overburden Deformation}

The overburden may be defined as the region that does not drain fluid from storage to directly compensate for the fluid withdrawn. The overburden lies above the reservoir. It has been assumed that deformation of the reservoir induces alterations in the bottom configuration of the overburden. Thus, the overburden is subjected to a prescribed displacement boundary condition. If an overburden indeed exists, deformation will depend on the particular reservoir geological setting, material properties, and the time scale involved.

Deformation of the overburden can be handled through two different approaches. The first is called the "tension center" or "nucleus of strain" approach, 6 which considers poro-elastic displacements around a contracting reservoir in a semi-infinite, isotropic rock medium. The integration of the displacement function over the volume of the flow region is carried out by semianalytic methods. This approach provides qualitative results rather than quantitative precision. The second and most general way of simulating overburden deformation is to make use of theories such as those of Biot. 7 It appears that such theories are quite realistic for simulating the overburden subjected to boundary loading.

Very few computer models have been developed so far to model subsidence in non isothermal systems. However, isothermal subsidence models have been developed in the past by hydrogeologists and petroleum engineers. Some of the available models are shown in Table B-III. 
Table B-III. Classification of some available models.*

\begin{tabular}{ccc}
\hline $\begin{array}{c}\text { Reservoir } \\
\text { Compaction } \\
\text { Models }\end{array}$ & $\begin{array}{l}\text { Overburden } \\
\text { Compaction } \\
\text { Models }\end{array}$ & $\begin{array}{c}\text { Coupled Reservoir-Overburden } \\
\text { Compaction } \\
\text { Models }\end{array}$ \\
\hline
\end{tabular}

ISOTHERMAL

One-, two-, or threedimensional fluid flow; one-dimensional consolidation; recoverable or nonrecoverable deformation parameters; nonlinear dependence of compressibility on stress. ${ }^{8}$
Multi-dimensional, singleor two-phase fluid flow; homogeneous, elastic overburden; semianalytic solution using "Nucleus of strain" theory.

One-, two-, or three- dimensional

fluid flow; one-, two-, or three-

dimensional deformation; generalized,

variable constitutive laws. 10

NONISOTHERMAL

Single-phase; one-, two-, or three-dimensional flow; one-dimensional consolidation; recoverable or nonrecoverable deformation parameters; nonlinear dependence of compressibility on stress. 11
One- or two-phase; one-, two-, or three-dimensional fluid flow; two-dimensional or axi-symetric deformation; elastic deformation properties; thermal effects on deformation. 12

* Refer to the following report for a more fully expanded overview of models.

"The Analysis of Subsidence Associated with Geothermal Development," Systems Control, Inc. for NSF Grant No. AER 75-17298 (Sept. 1976). 
Discussion of a solution

Assess the adequacy of existing mathematical models for estimating land subsidence and lateral ground deformation. The final report will Include recommendations for additional research necessary to increase the capability for estimating subsidence.

Research Objectives

Several computer models of varying levels of sophistication exist for purposes of simulating subsidence (see Table B-III). The immediate objective is to evaluate the merits of these models by applying them to known field situations.

The principal objectives of the evaluations should include:

- Determine the adequacy of the one-dimensional consolidation approach in dealing with deep-seated reservoirs.

- Evaluate the reliability and accuracy of the results obtained with the generalized models that couple the flow equation and the force balance equation. Examine the quality of available field data to see if they are sufficient to provide reasonable input parameters for these models. Study the effort associated with these models to see if it justifies the sophistication.

- Determine the best approach to model reservoir and overburden deformations. Determine whether they should be treated together or treated separately with appropriate coupling.

- Determine the importance of temperature effects. Examine an isothermal approach to see if it is adequate insofar as subsidence calculations are concerned. 
Results of the above evaluations will help to choose the most promising approach for subsidence modeling, i.e., one that combines accuracy with economy of effort in relation to the quality of field data available.

Selection of an appropriate model(s) will lead to the second level of research activity including:

- simulation of hypothetical problems. This would help in gaining an insight into complex field systems and the sensitivity of the system behavior to geometric, material, and other parameters. In addition, these simulations would assist in studying the problem of controlling subsidence through optional injection patterns and well spacing.

- If the first phase of activity reveals the need for new models or greatly modified existing models, such developments will form part of the second phase: Improvement of simulation logic through the use of better constitutive laws as revealed by answers to the above evaluations. This effort anticipates new information obtained from the field part of Research Category 1.

Research Project Tasks

The tasks indicate the major categories of action. Detailed recommendations for specific work would be required in a proposal, and modifications, as appropriate, would be made during the research. Figure B-14 shows an overview of these tasks.

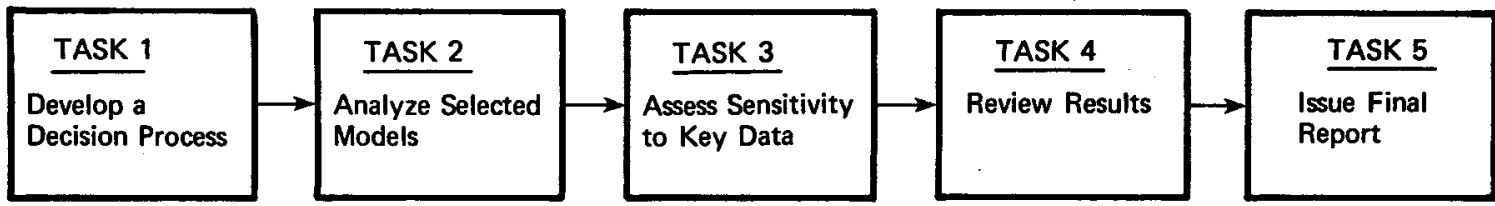

XBL $774-8435$

Figure B-14. General Schedule: Subsidence Modeling Confirmation and Compar ison. 
Task 1 Develop a Decision Process. The first task will be the development of a decision process to select a range of models for evaluation.

Task 2 Analyze Selected Models. Analysis and comparisons of selected models will be a critical aspect of the project. ${ }^{14}$ Consideration should be given to using actual field data or a simulated scenario of field data if such data are lacking in quality or quantity.

Task 3 Assess Sensitivity to Key Data. Evaluate models and assess sensitivity to key input field data.

Task 4 Review Results. Results of the research in Tasks 1,2 , and 3 will be described in detail for review during a seminar or by a selected committee.

Task 5 Issue Final Report.

A detailed description of the entire evaluation will be supplied such that a third party could duplicate the evaluation process. Thus, the report would provide a means to show independent conclusions.

\section{Priority and Interfaces}

The evaluation of existing models has a high priority. Modeling can help establish priorities for other research by indicating the areas that lack clarity. Models will also aid planners in assessing the consequences of geothermal development. 
The results of model evaluation can assist the testing phases of Categories 3 and 6 , which focus on instrumentation for monitoring. The assessments may also provide direction to research in physical processes and laboratory tests, Categories 5 and 7 . The most important aspect of modeling will be the support in planning the operational policy outlined in Category 9.

Summary of Product and Milestone

The major milestone and product of the research will be a final report of the results of the evaluation and recomendations for research. A seminar or workshop will be arranged so that industry, government, and public experts can share their concepts on the research analysis and their recommendations for future model development. Additional model development is indicated as an additional research project (Figure 3-1), should a need exist. 


\section{REFERENCES}

1. T. W. Lambe and R. V. Whitman, Soil Mechanics (John Wiley and Sons, Inc., NY, 1969).

2. G. Gambolati, and R. A. Freeze, "Mathematical Simulation of the Subsidence of Venice. II. Results," Water Resour. Res. 10, pp. 564-577 (1974).

3. D. C. Helm, "One-Dimensional Simulation of Aquifer System Compaction Near Pixley, California. I. Constant Parameters," Water Resour. Res. 11, pp. 455-478 (1975).

4. W. B. Stilwell, W. K. Hall, and J. Tawhai, "Ground Movement in New Zealand Geothermal Fields," Proc. Second U. N. Symp. on the Development and Use of Geothermal Resources, Sec. 5, pp. 1427-1434 (1976) .

5. G. A. Nystrom, "A Review of Soil Models for Subsidence Analysis," Technical Memorandum 5139-400-10, Systems Control Incorporated, Palo Alto, California, November 1975.

6. J. Geertsma and G. Van Opstal, "A Numerical Technique for Predicting Subsidence Above Compacting Reservoirs, Based on the Nucleus of Strains Concept," Verh. K. Ned. Geol, Mijnbouwkd. Genoot. Geol. Ser. 28, pp. 63-78 (1973).

7. M. A. Biot, "Theory of Elasticity and Consolidation for a Porous Anisotropic Solid," J. Appl. Phys. 26, 182 (1955).

B. T. N. Narasimhan, "A Unified Numerical Model for SaturatedUnsaturated Groundwater Flow," Ph. D. dissertation, University of California, Berkeley, 1975. 
9. A. Finol and S. M. Faroug Ali, "Numerical simulation of Oil Production with Simultaneous Ground Subsidence," J. Soc. Pet. Eng. 15, 411-424 (1975).

10. R. S. Sandhu and E. L. Wilson, "Finite Element Analysis of Land Subsidence," Land Subsidence, Proc. Tokyo Symposium, Int. Assoc. Sci. Hydro. 2 , pp. 383-400 (1969).

11. M. J. Lippmann, T. N. Narasimhan, and P. A. Witherspoon, "Numerical Simulation of Reservoir Compaction in Liquid Dominated Geothermal Systems," Second Intern. Symp. on Land Subsidence, Anaheim, CA (1976) .

12. Systems, Science and Software, La Jolla, CA.

13. R. L. Pierce, "Reducing Land Subsidence in the wilmington Oil Field, by Use of Saline Waters," Water Resour. Res. $\underline{6}$, pp. 1505-1514 (1970).

14. R\&D Associates, Evaluation of Geothermal Energy Exploration and Resource Assessment. Volume I - A Review of Geothermal Subsidence Modeling. Contract No. EY-76-C-03-1269, RDA-TR-0400-001 (in progress). 


\section{RESEARCH CATEGORY 9}

\section{Reservoir Operational Control Policy*}

\section{Background}

Research projects in Categories 1 through 8 will provide information on the physical processes of subsidence, the means to estimate potential subsidence, and the guidelines for evaluating the effects of subsidence. This knowledge would be applied to current and future geothermal reservoir operations.

\section{Statement of the Problem}

Presently, there are no guidelines to assist management decisions regarding where to drill or operate production, injection, and observation wells. An understanding of potential subsidence of a geothermal resource would help develop operational policy.

\section{Discussion of the Solution}

Guidelines for reservoir management and operations policy should be developed. These guidelines would be used for making decisions throughout the life of the geothermal reservoir.

* Announced in the Commerce Business Daily, September 13, 1976 as Category 10 . 


\section{Research Objectives}

This research category is the target element of the research program. Within this element a major portion of the program goals are attained; the earlier research projects supply the supporting information.

The objectives of this research category are to provide operational guidelines to:

- Distinguish naturally occurring subsidence from that possibly caused by geothermal operation.

- Operate a geothermal field so that adverse effects due to subsidence will be prevented or minimized.

\section{Research Project Tasks}

Figure B-15 shows some activities for Category 9. The research program will be accomplished with two projects. Project 1 (Tasks 1 through 4) will acquire reservoir management information and review results from other research categories. Project 2 (Tasks 1 through 3) will develop guidelines for planners, developers, and operators of geothermal projects.

PROJECT 1 - INDUSTRY EVALUATION

Task 1 Compile Information on Reservoir Management Problems.

Information will be acquired on problems facing operators of geothermal projects. The emphasis will be on investigating production problems resulting from subsidence. Some of these problems are caused by: 


\section{PROJECT 1}

\section{Industry Evaluation}

Task 1

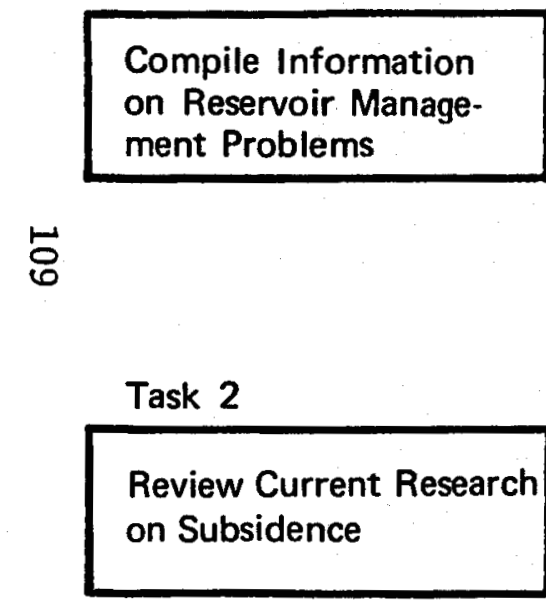

Task 3

Assess Current

Research

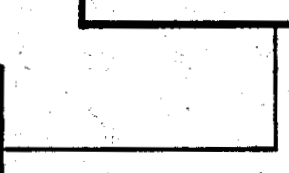

Review Current

Task 4

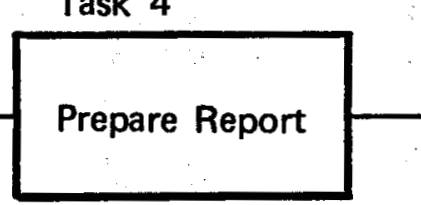

Task 2

Develop Specifications

for Management Tools

\section{PROJECT 2}

\section{Guidelines and Procedures}

Task 1

Develop Guidelines for

Decision Making for

Reservoir Operations

Management

Task 3

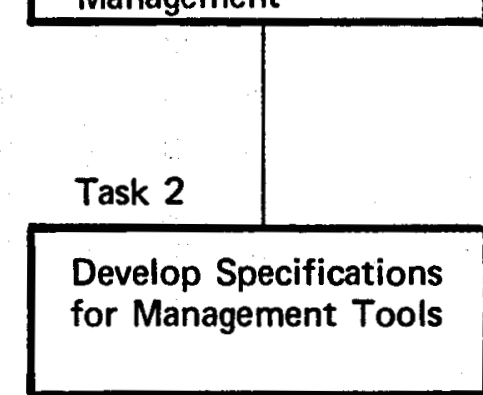

Develop Guidelines

for Reservoir Use

Figure B-15. General Schedule: Reservoir Operations Management. 
- Well spacing and location.

- Injection techniques.

- Methods for treat extraction.

Task 2 Review Cureent Research on Subsidence. Categories 1 through 8 will be reviewed for results that will be useful in solving the problems identified in Task 1.

Task 3 Assess Current Research.

Problems solved using the results of Categories 1 through 8 will be identified. Additional research will be outlined to resolve other problems; redirection of current research may be recommended.

Task 4 Prepare Report.

A report will be prepared, providing information on reservoir management problems that should be solved by the present subsidence research program.

PROJECT 2 - GUIDELINES AND PROCEDURES

Task 1 Develop Guidelines for Decision Making.

The operations management decision-making process will be identified. Subsidence theory will be applied to decision making and guidelines for decisions will be developed. 
Task 2 Develop Specifications for Management Tools.

Available options in management tools will be investigated. For example, computer codes may be practical for assessing reservoir development.

\section{Task 3 Develop Guidelines for Reservoir Use.}

Guidelines for using a geothermal reservoir and minimizing the effects of potential subsidence will be formulated.

\section{Priority and Interfaces}

This category depends on the results obtained in the previous Research Categories. However, this does not mean that it should have lower priority. Tasks 1 through 4 should be started early in the second year of research to influence work in other categories.

The results will provide guidance to direct measurement instrumentation (Category 3) and indirect technique development (Category 6). In addition, these tasks may provide information useful in planning physical process research (Category 5) and laboratory testing (Category 7).

\section{Summary of Products and Milestones}

The following documents will result from projects in this Category:

- An interim report on reservoir management problems related to subsidence.

- An operational policy based on results from the total geothermal subsidence research program. 
This report was done with support from the United States Energy Research and Development Administration. Any conclusions or opinions expressed in this report represent solely those of the author(s) and not necessarily those of The Regents of the University of California, the Lawrence Berkeley Laboratory or the United States Energy Research and Development Administration. 